\title{
AN ANALYSIS OF TEMPERATURE AND LIGHT SENSITIVITY IN tigrina MUTANTS OF BARLEY
}

\author{
by
GIORGIO CASADOROI), GUNILLA HØYER-HANSEN, C. GAMINI KANNANGARA and SIMON P. GOUGH

Department of Physiology, Carlsberg Laboratory,

Gamle Carlsberg Vej 10, DK-2500 Copenhagen, Valby

1)Permanent address: Istituto di Genetica, Via Amendola 165/A, I-70126 Bari,Italy

Keywords: Thylakoid polypeptides, carotenoids, chlorophyll $a_{743}$, high pressure liquid chromatography, electron microscopy, lycopene, monoepoxyxanthophyll

\begin{abstract}
Quantitative determinations of chlorophylls, carotenes and xanthophylls were carried out by high pressure liquid chromatography on the nuclear gene mutant tigrina-o34. In the dark the mutant accumulates lycopene and protochlorophyllide at $23^{\circ} \mathrm{C}$ but almost none at $30^{\circ} \mathrm{C}$, while xanthophylls are deficient only at $23^{\circ} \mathrm{C}$. In the light, lycopene accumulation and $\beta$-carotene as well as xanthophyll deficiency is severe at $23^{\circ} \mathrm{C}$, whereas an improved content of $\beta$-carotene and xanthophyll is observed at $30^{\circ} \mathrm{C}$. An improved content can also be achieved by growing mutant seedlings in red light of wavelengths longer than $650 \mathrm{~nm}$ at $23^{\circ} \mathrm{C}$.

Under conditions where lycopene accumulates in the dark the presence of abnormal membrane structures is correlated with a deficiency in certain membrane polypeptides, e.g. the $\alpha, \beta$ subunits of coupling factor.

Under conditions of severe $\beta$-carotene deficiency in light grown seedlings, photodynamic destruction of chloroplast ribosomes and preferential accumulation of light harvesting chlorophyll $a / b$-protein is observed. Eventually, the chloroplast structure disintegrates.

Under conditions of simultaneous lycopene accumulation and $\beta$-carotene as well as lutein deficiency the chlorophyll aggregates into a non-fluorescing form absorbing at $743 \mathrm{~nm}$. This form is part of a complex insoluble in $2 \%$ SDS and containing lycopene, chlorophyll $a$ and protein.
\end{abstract}

Tigrina mutants at other loci have been characterized as to their temperature and light sensitivity.

Abbreviations: $\mathrm{CF}_{1}=$ chloroplast coupling factor; $\mathrm{Chl}=$ chlorophyll; $\mathrm{Chl}-\mathrm{P}=$ chlorophyll-protein; $\mathrm{HPLC}=$ high pressure liquid chromatography; $\mathrm{kD}=$ kilodalton; $\mu \mathrm{E}=$ micro Einsteins; $\mathrm{PAGE}=$ polyacrylamide gel electrophoresis; $\mathrm{SD}=$ standard deviation; $\mathrm{SDS}=$ sodium dodecyl sulfate. 


\section{INTRODUCTION}

The tigrina phenotype of barley, characterized by alternate transverse green and necrotic bands in the leaf (Figure l), is only expressed when the tigrina mutants are grown under alternating periads of darkness and light (36). In continuous light the tigrina mutants are uniformly coloured and usually chlorophyll deficient while in the dark some are pale green due to the accumulation of protochlorophyllide in amounts exceeding that found in the wild-type (Figure 2) (28). The tigrina mutants are therefore considered to be defective in the regulation of chlorophyll biosynthesis $(10,21,28,37)$. In tigrina-d ${ }^{12}$, tigrina$b^{23}$ and tigrina-o $o^{34}$ it was shown that the lesions are in control mechanisms operating normally in the dark to restrict $\delta$-aminolevulinate formation and thereby prevent excessive protochlorophyllide accumulation (14). In tigrina$b^{23}$ and tigrina-o ${ }^{34}$ excessive protochlorophyllide
Figure 2. Phenotypes displayed by tigrima- $a^{34}$.

A. Wild-type and tigrina-0 34 grown in the dark at $23^{\circ} \mathrm{C}$. B. Wild-type and mutants mixed with heterozygotes grown in the dark at $30^{\circ} \mathrm{C}$. C. Wild-type and mutant grown in $>600 \mathrm{~nm}$ at $23^{\circ} \mathrm{C}, \mathrm{D} .>650 \mathrm{~nm}$ red light at $23^{\circ} \mathrm{C}$ and $\mathrm{E}$. in $>650 \mathrm{~nm}$ red light at $30^{\circ} \mathrm{C}$.

accumulation in the dark was accompanied by partial blocks in the biosynthesis of carotenoids (29). In tigrina-o 34 lycopene accumulation was observed. This mutant is particularly interesting because under constant light at the low temperature $\left(20-23^{\circ} \mathrm{C}\right)$ deficiencies are observed of chlorophyll (28), chloroplast ribosomes and proteins synthesised thereon (17). These defects tend to normalise at the high temperature of $30^{\circ} \mathrm{C}$. At the high temperature other abnormalities are also reduced such as the amount of abnormal plastid membrane structures (17) and of chlorophyll $a_{743}(28)$.
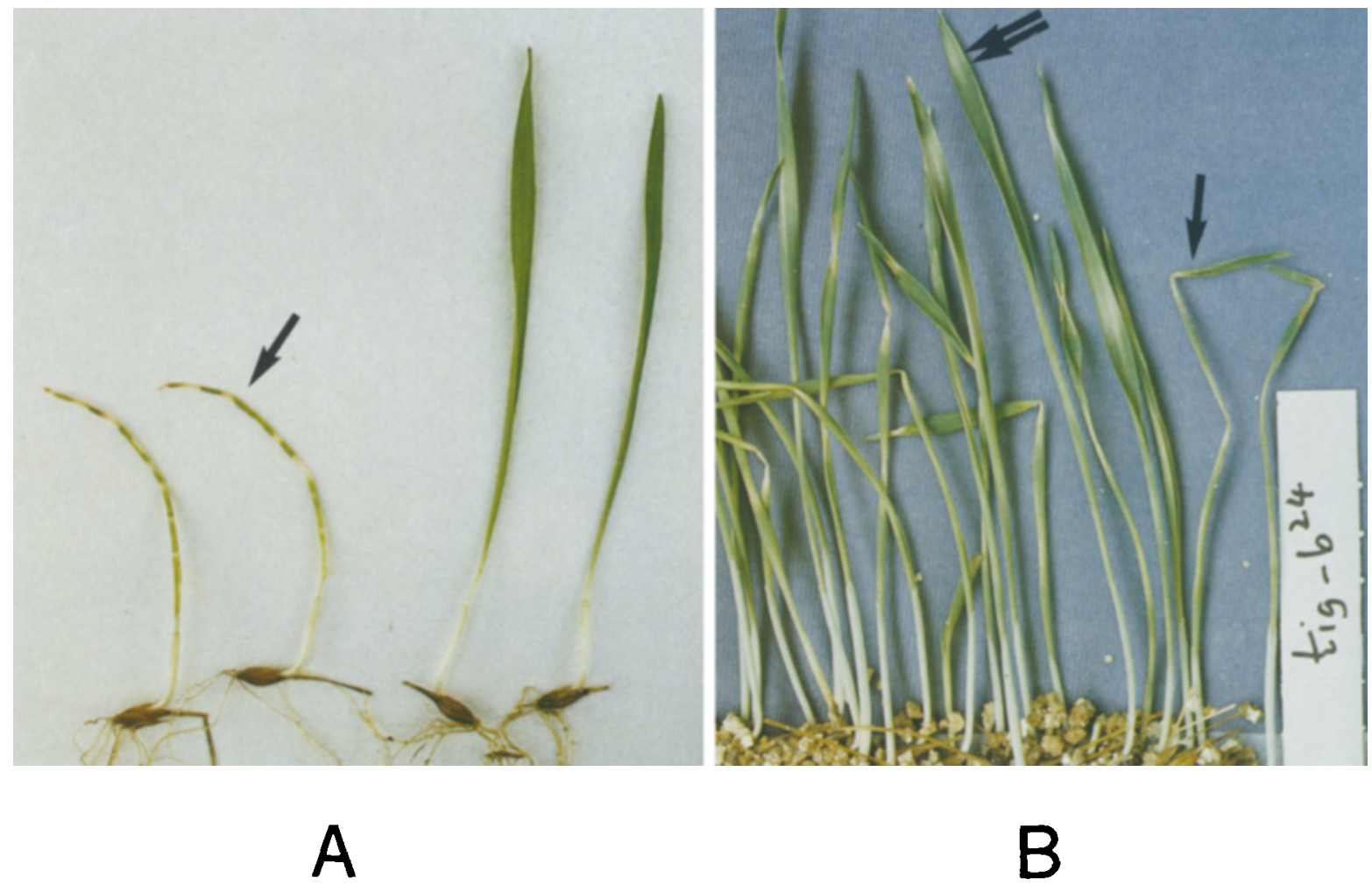

Figure 1. Phenotypes shown by tigrina mutants grown under light-dark cycles.

A. The tigrina phenotype exemplified by tigrina-d 12 grown in the green-house. B. The zonata (arrow) and tigrina (double arrow) phenotypes shown by tigrina- $b^{24}$ grown in the growth chamber. 

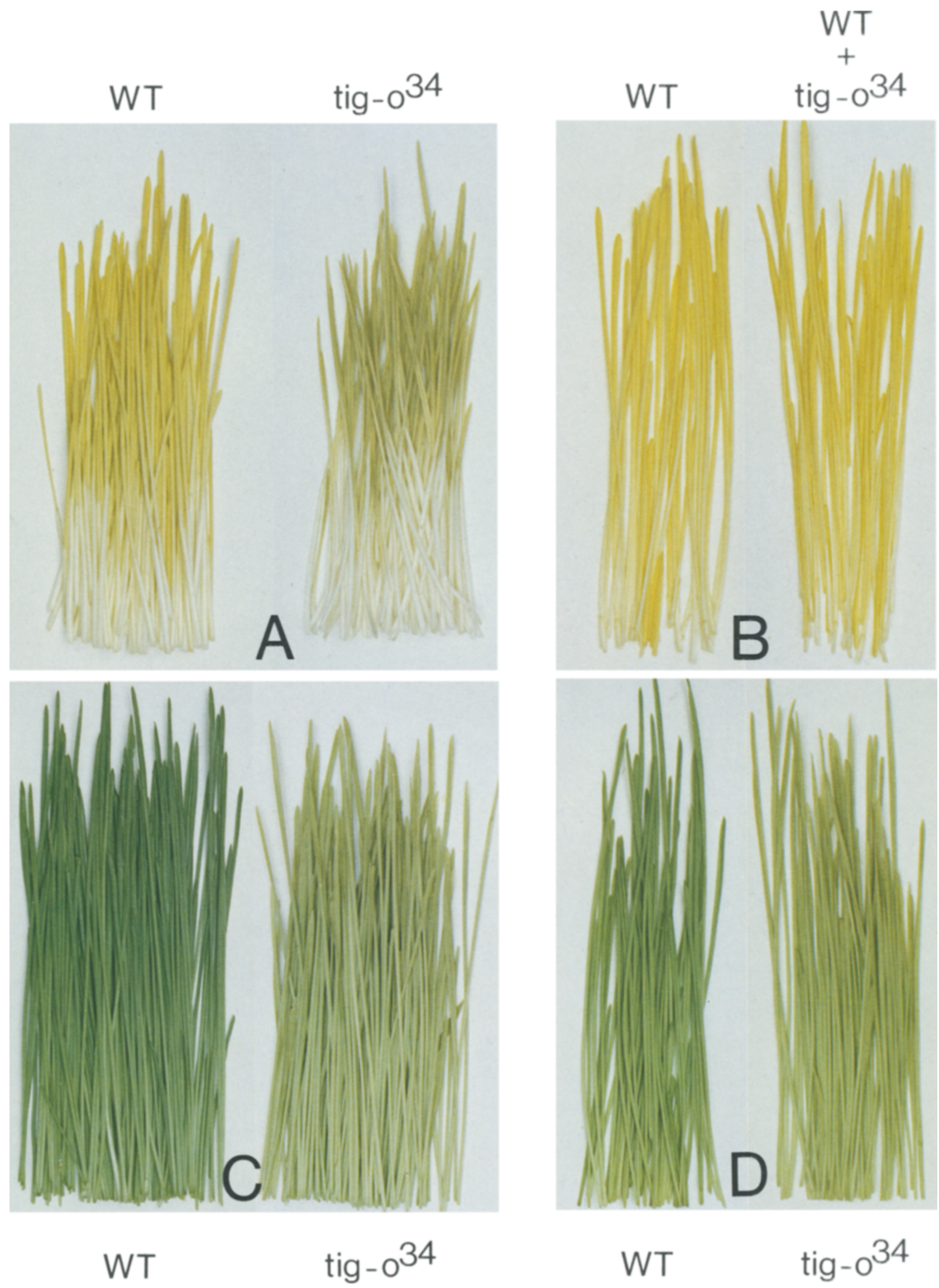

WT

tig-0 34 


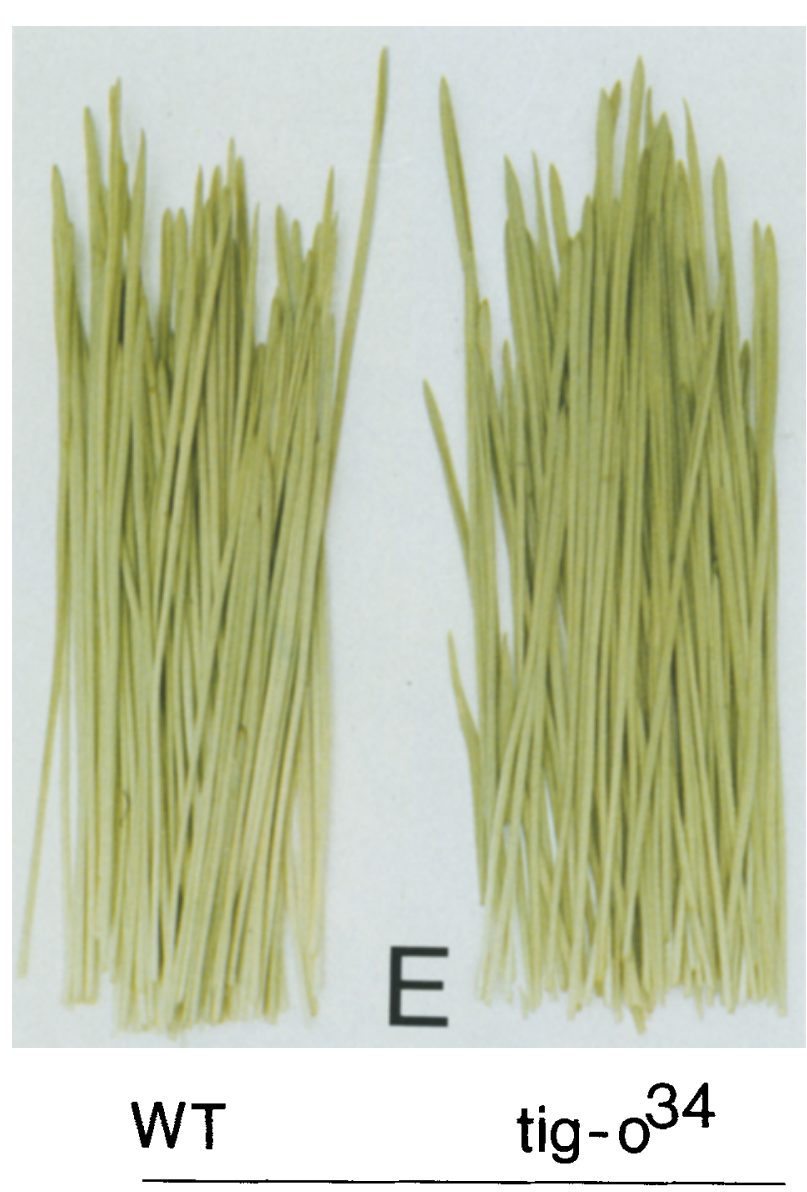

This paper shows that in tigrina-o $o^{34}$ an increase in growth temperature coordinately affects the defect in carotenoid biosynthesis and the defective regulation of chlorophyll biosynthesis in the dark. In the light changes in pigment composition in tigrina-o ${ }^{34}$ grown at high and low temperature and under high and low intensity red lights are related to ultrastructural and molecular abnormalities in the plastids. The effect of temperature and light conditions on the phenotype of other tigrina mutants is also presented.

\section{MATERIALS AND METHODS}

\subsection{Plant material and growth conditions}

Seeds used were wild-type barley (Hordeum vulgare cv. Svalöfs Bonus), the mutant tigrina-o 34 and its heterozygote in a 1:1.2 ratio (28), seeds of homozygous tigrina- $b^{24}$, tigrina-c, tigrina-j ${ }^{28}$, seed material segregating for tigrina mutants at the tigrina- $a$, tigrina- $b$, tigrina-d, tigrina-e, tigrina- $f$, tigrina-m, tigrina- $n$ loci and for albozonata- 1 . Seeds were germinated in vermiculite moistened with tap-water. They were grown for seven days prior to analysis. Seedlings were grown either at $23^{\circ} \mathrm{C}$ or $30^{\circ} \mathrm{C}$ in complete darkness or under continuous illumination with white light or red light. Two different red lights were used; one with wave-lengths above $600 \mathrm{~nm}$ and the other above $650 \mathrm{~nm}$. Seedlings were also grown in alternating periods of 8 hours dark and 16 hours light controlled by a time switch. For the discontinuous illumination experiments white light or red light with wave-lengths above $600 \mathrm{~nm}$ or $650 \mathrm{~nm}$ were used. Except when grown at $30^{\circ} \mathrm{C}$ in the dark or in continuous red light at wave-lengths above $650 \mathrm{~nm}$, leaves of tigrina-o $0^{34}$ could be distinguished by their colour in white light from phenotypically wild-type heterozygotes. The leaves were frozen in liquid nitrogen in green safe light and sorted in white light at liquid nitrogen temperatures. Under these conditions protochlorophyllide was not photoconverted and pigments were protected against photooxidation by reason of the nitrogen atmosphere.

\subsection{Light sources and energies}

Two different white light sources were used. Four Osram Fluora 20W strip lights providing an intensity of $55 \mu \mathrm{E} \cdot \mathrm{m}^{-2} \cdot \mathrm{sec}^{-1}$ and two Philips $\mathrm{TL}, 40 \mathrm{~W}$ striplights $\left(15 \mu \mathrm{E} \cdot \mathrm{m}^{-2} \cdot \mathrm{sec}^{-1}\right)$ were used. Red light with wave-lengths above $600 \mathrm{~nm}$ (> 600nm) was obtained from the stronger light source using a Rohm and Haas filter No. 502 (red). The light intensity was measured as $20 \mu \mathrm{E} \cdot \mathrm{m}^{-2} \cdot \mathrm{sec}^{-1}$. Red 502 combined with blue 625 gave $>600 \mathrm{~nm}$ red light with an intensity of $2.5 \mu \mathrm{E} \cdot \mathrm{m}^{-2} \cdot \mathrm{sec}^{-1}$. Red light with wave-lengths above $650 \mathrm{~nm}(>650 \mathrm{~nm})$ was obtained from the same light source using filter No. 602 (blue) and No. 502 (red) (Figure 3). The light intensity was $1.4 \mu \mathrm{E} \cdot \mathrm{m}^{-2} \cdot \mathrm{sec}^{-1}$. The red filters formed the top of a large box $(100 \times 50 \times 30($ depth $)) \mathrm{cm}^{3}$ in which the plants were grown. Light intensities were measured using an LI-COR photometer model LI-185B and an LI-COR quantum sensor.

\subsection{Extraction of pigments and preparation for their quantitive determination by high pressure liquid chromatography}

Leaves were harvested by cutting them below the coleptile. One gram of plant material or sin- 


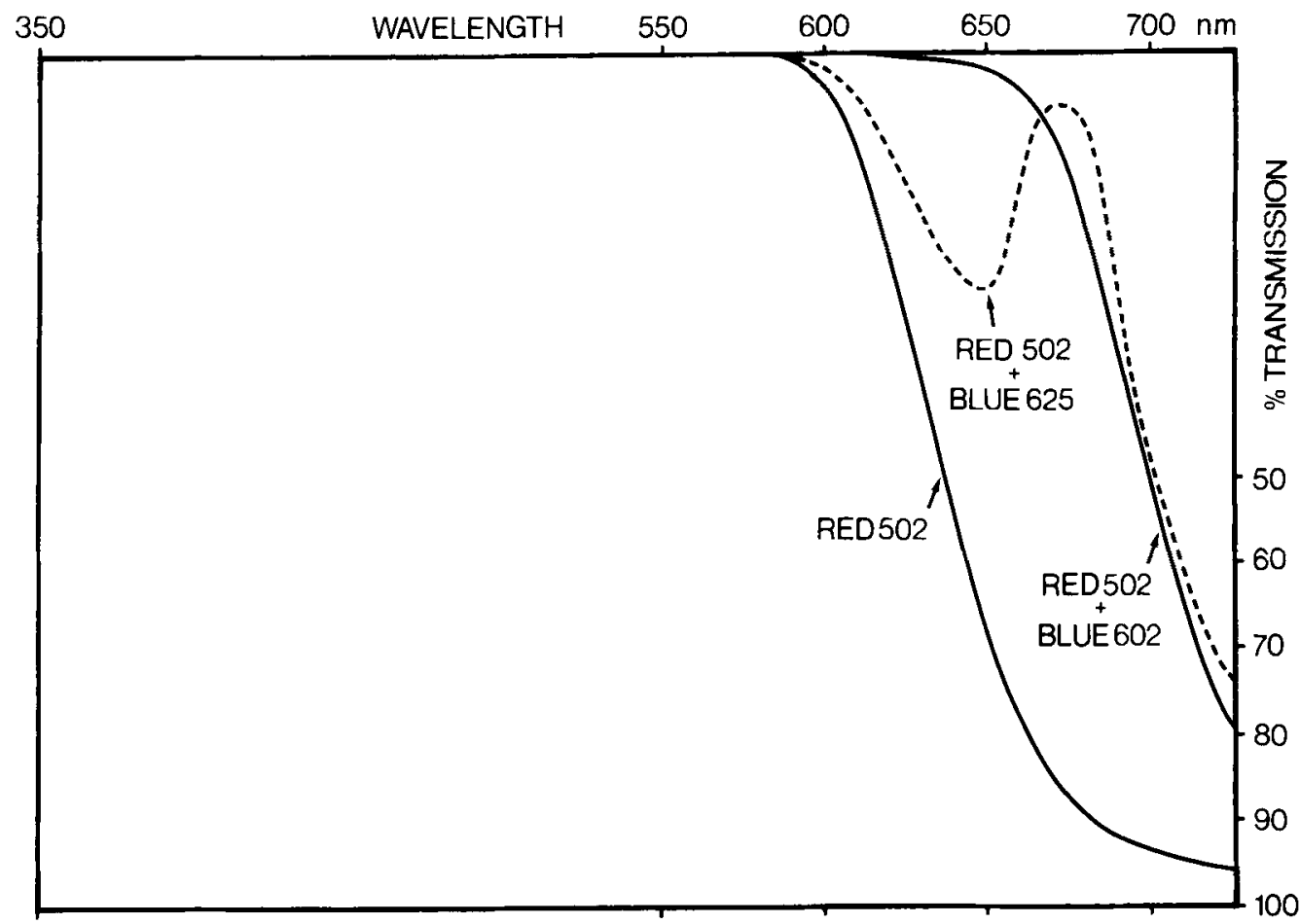

Figure 3. Absorption spectra of filters used to obtain different red lights.

Blue 602 and red 502 were combined to produce red light of wave-lengths above $650 \mathrm{~nm}$. Red 502 was employed to give red light with wave-lengths above $600 \mathrm{~nm}$. When this filter was used alone an intensity of $20 \mu \mathrm{E} \cdot \mathrm{m}-2 \cdot \mathrm{sec}^{-1}$ was obtained. Red 502 combined with blue 625 gave $>600 \mathrm{~nm}$ red light with an intensity of $2.5 \mu \mathrm{E} \cdot \mathrm{m}^{-2} \cdot \mathrm{sec}^{-1}$.

gle plants were ground in a mortar with liquid nitrogen and respectively 200 or $10 \mathrm{mg}$ $\mathrm{NaHCO}_{3}$. All operations were carried out in dim light or green safe light. For the larger amount of tissue the fine powder was transferred with acetone to a Buchner filter funnel and washed with $50 \mathrm{ml}$ of acetone. Ten $\mathrm{ml}$ of ethyl acetate was added to the filtrate and it was evaporated to final volume of 1 or $2 \mathrm{ml}$ under a stream of nitrogen. If an aqueous layer formed it was dispersed by the addition of more acetone. The powdered single leaves were transferred with $5 \mathrm{ml}$ acetone to a centrifuge tube and allowed to stand for some minutes in order to extract the pigments. After centrifugation one $\mathrm{ml}$ of ethyl acetate was added to the supernatant and the combined solution was evaporated as above to 50 or $100 \mu 1$. The pigments in the reduced extracts were then quantitively determined by high pressure liquid chromatography (HPLC).

\subsection{Determination of pigments by high pres- sure liquid chromatography}

Chlorophylls and carotenoid pigments from plants grown in the light were injected into the separatory system by an automatic injection unit (WISP 710B) and separated on a $\mathrm{C}_{18}$ reverse phase contained in a plastic column (Radial Pack C18) and compressed in an RCM-100 unit. Elution was performed using a linear gradient of $90 \%$ methanol to $100 \%$ ethyl acetate over a period of 20 minutes followed by further isocratic elution with ethyl acetate for 5 minutes. The gradient was generated by two pumps controlled by a System Controller. The flow rate was $1 \mathrm{ml}$ per minute. The eluting pigments were detected at $430 \mathrm{~nm}$ at a sensitivity of 0.2 by a 450 Variable Wavelength Detector. The signal from the detector was integrated and the amounts of pigments calculated by a Data Module, programmed using factors obtained by linear regression of known 
amounts of standard pigments and integrated peak area. All high pressure liquid chromatography equipment was manufactured by Waters. Protochlorophyllide and carotenoid pigments from plants grown in the dark were separated using the same system except for the introduction of $5 \mathrm{~mm}$-tetrabutyl ammonium phosphate (Kodak) into the $90 \%$ methanol. In the presence of this anion-pairing reagent protochlorophyllide was retained for a longer time on the column.

\subsection{Preparation of standard pigment solutions}

All pigments were prepared in dim light or in green safe-light. Protochlorophyllide was prepared from dark grown barley shoots incubated overnight with their cut ends in $0.01 \mathrm{M}-\delta$ aminolevulinate. The shoots were ground in liquid nitrogen, extracted with acetone: $0.3 \mathrm{M}-\mathrm{NH}_{3}$, $80: 20 \mathrm{v} / \mathrm{v}$ and filtered. The protochlorophyllide was transferred to diethyl ether by the addition of an equal volume of ether and saturated $\mathrm{NaCl}$ solution. The ether phase, containing protochlorophyllide and carotenoids, was washed free of acetone with water. Carotenoids were then separated from the protochlorophyllide. To 1 volume of ether was added 4 volumes of petroleum ether, 0.1 volume of a mixture $(4: 1 \mathrm{v} / \mathrm{v})$ of methanol and $10 \mathrm{~mm}-\mathrm{NH}_{3}$. Protochlorophyllide was extracted into the ammoniaical methanol leaving all carotenoid pigments in the other phase. The protochlorophyllide solution was then washed with an equal volume of petroleum ether. The methanolic solution of protochlorophyllide was then diluted with saturated $\mathrm{NaCl}$ solution and the protochlorophyllide concentrated by absorbtion on a cartridge of $\mathrm{C}_{18}$ reverse phase material (Waters Sep-Pak $C_{18}$ ). The Sep-Pak $C_{18}$ was pre-activated by passing $10 \mathrm{ml}$ acetone and then $5 \mathrm{ml}$ of $\mathrm{H}_{2} \mathrm{O}$. Protochlorophyllide was eluted with acetone and concentrated to a small volume under a stream of nitrogen. The concentration of protochlorophyllide was estimated in $80 \%$ acetone using $\mathrm{E}_{\mathrm{mM} 628}=$ 34.5 (13). Standard solutions of chlorophyll $a$ and $b$, lutein, violoxanthin, neoxanthin and $\beta$ carotene were prepared in the following manner. A solution enriched in leaf xanthophylls was obtained by grinding $50 \mathrm{~g}$ green leaves in liquid nitrogen and $1 \mathrm{~g}$ solid $\mathrm{NaHCO}_{3}$ and extracting the powder on a Buchner funnel with $50 \%$ acetone. The residue was set aside for extraction of chlorophylls and $\beta$-carotene. To the filtrate was added 0.2 volumes of chloroform. Acetone was then added until the two phases were dispersed. The mixture was then poured into 4 volumes of distilled water in a measuring cylinder. Pigment-containing droplets of the mixture fell through the water, were washed free of acetone and collected at the bottom as a relatively small volume of chloroform containing the pigments. The chloroform was washed several times with water removing each time the water and any solids that collected at the interphase after centrifugation. The chloroform solution of pigments was then dried over anhydrous $\mathrm{NaSO}_{4}$ and the three xanthophyll pigments separated by reversed phase chromatography on thin layer plates (Whatman $\mathrm{RC}_{18}$ ) using a solvent system of $90 \%$ methanol:ethyl acetate, 40:10 v/v. The separated xanthophylls were scraped off, eluted with acetone, concentrated under a stream of nitrogen and the concentration determined in ethanol using the extinction coefficients collected by DAvIS (6). The residue remaining from the extraction of xanthophylls was extracted with acetone until chlorophylls and $\beta$-carotene were removed and the acetone filtered. The chlorophylls were then separated from the $\beta$-carotene using an activated $\mathrm{C}_{18}$ cartridge (7). The acetone was diluted with water and the pigments absorbed on the cartridge. Chlorophylls were then eluted with methanol and $\beta$-carotene with acetone. Pigments were separated on reversed phase $\mathrm{C}_{18}$ thin layer plates in solvent systems of $90 \%$ methanol:ethyl acetate $50: 50 \mathrm{v} / \mathrm{v}$ and $10: 90$ $\mathrm{v} / \mathrm{v}$ consecutively. Pigments were eluted with acetone and the concentrations determined spectrophotometrically of the chlorophylls (25) and for $\beta$-carotene (6). Lycopene was purified from tomato paste (Italian dobbelconcentrato) as described in (19) and the concentration of alltrans-lycopene determined spectrophotometrically (6). After determination of the concentration of lycopene and the five chloroplast pigments the solutions were combined and concentrated to give a mixture of known composition. Different amounts of the mixture were injected into the high pressure liquid chromatograph in order to calibrate the response for each 
pigment. Protochlorophyllide was calibrated by injecting it separately. Concentrations of the unknown epoxy-xanthophyll eluting between lutein and violoxanthin was determined using the same factor as determined for lutein.

\subsection{Spectrophotometric and spectrofluorometric measurements}

Absorption spectra were determined using an Aminco DW-2A. Low temperature fluorescence emission spectra were obtained as described by SIMPSON and vON WETTSTEIN (32).

\subsection{Isolation of ribosomes, purification of thylakoids, and SDS-PAGE}

Ribosomes were isolated as described earlier (17). In the preparations of ribosomes the ratio of $\mathrm{A}_{260}$ to $\mathrm{A}_{280}$ varied between $1.6-1.9$ for crude ribosomes isolated from dark-grown plants and between $1.6-1.8$ for those isolated from red lightgrown plants. After separation of $70 \mathrm{~S}$ and $80 \mathrm{~S}$ ribosomes on a $10-30 \%$ sucrose gradient, the ribosomal proteins were analysed by SDSPAGE. Internal plastid membranes were isolated and purified according to (18) and subjected to SDS-PAGE. The molecular weights of the separated polypeptides were determined by use of molecular weight markers. (Bovine serum albumin 68,000 , ovalbumin 43,000 , chymotrypsinogen A 25,000 and cytochrome $c 12,400$ ).

\subsection{Electron microscopy}

Tissue samples from dark-grown and red lightgrown seedlings were collected and fixed under dim green light and red light, respectively. Specimens were sampled at different levels along the primary leaf, as illustrated in Figure 12. Tissue samples were prepared for electron microscopy by fixation in $3 \%$ glutaraldehyde and $10 \mathrm{~mm}$ $\mathrm{MgCl}_{2}$ in $0.05 \mathrm{M}$-cacodylate buffer, $\mathrm{pH} 6.9$, and postfixed in $1 \%$ osmium tetroxide in the same buffer. Thereafter they were processed as described earlier (17).

\subsection{Measurement of $\mathrm{CO}_{2}$ fixation}

The five $\mathrm{cm}$ top portion of the leaf was cut into 8 pieces and floated for $10 \mathrm{~min}$ in $0.4 \mathrm{ml}$ of distilled $\mathrm{H}_{2} \mathrm{O}$ containing $1 \mu \mathrm{Ci}$ of $\mathrm{NaH}^{14} \mathrm{CO}_{3}$ under $1000 \mu \mathrm{E} \cdot \mathrm{m}^{-2} \cdot \mathrm{sec}^{-1}$ of white light (Osram HQI lamp). After the incubation $1 \mathrm{ml}$ of boiling meth- anol was added, the leaf pieces ground in a mortar and an aliquot of the methanol extract counted.

\section{RESULTS}

\subsection{The pigment composition of tigring-0.34 and} the wild-type grown in the dark at $23^{\circ} \mathrm{C}$ and $30^{\circ} \mathrm{C}$

In this section it is shown that the accumulation of excess protochlorophyllide in tigrina-o $0^{34}$ at the lower temperature was associated with a defect in carotenoid biosynthesis because both defects were reversed at the higher temperature. Figure 4A illustrates the separation of protochlorophyllide and carotenoids from mutants grown at the lower temperature and from the mixture of wild-type and mutants grown at the higher temperature. As can be seen large amounts of protochlorophyllide (peak 1) and lycopene (peak 8) were present in the mutant grown at the lower temperature. At the higher temperature the mutants could not be distinguished by eye from the phenotypic wild-type although they were known to be present in a ratio of about 1:1 (Figure 2B). However, pigments extracted from mixed leaves of these two genotypes contained low levels of protochlorophyllide and lycopene. In order to determine the pigment composition in the mutant at $30^{\circ} \mathrm{C}$ analyses of extracts of single seedlings were carried out. Table I shows that the leaf identified as a mutant because of its small content of lycopene, had wild-type levels of $\beta$-carotene and the other pigments. Therefore, apart from the presence of a small amount of lycopene, the pigment composition of the mutant leaves grown in the dark at $30^{\circ} \mathrm{C}$ is similar to that of the wild-type.

Both mutant and wild-type contained a pigment (Figure 4A, peak 4) which eluted between violoxanthin (peak 3) and lutein (peak 5) and had a spectrum very similar to lutein. The shift of the absorption maxima towards the blue caused by the addition of a drop of concentrated $\mathrm{HCl}$ and the magnitude of this shift (Figure 5) indicated that the pigment was a monoepoxycarotenoid (6). The two neighbouring peaks were lutein (a dihydroxyxanthophyll) and violoxanthin (a diepoxydihydroxyxanthophyll). Therefore the elution position of the pigment suggests that it was a monoepoxydihydroxy- 


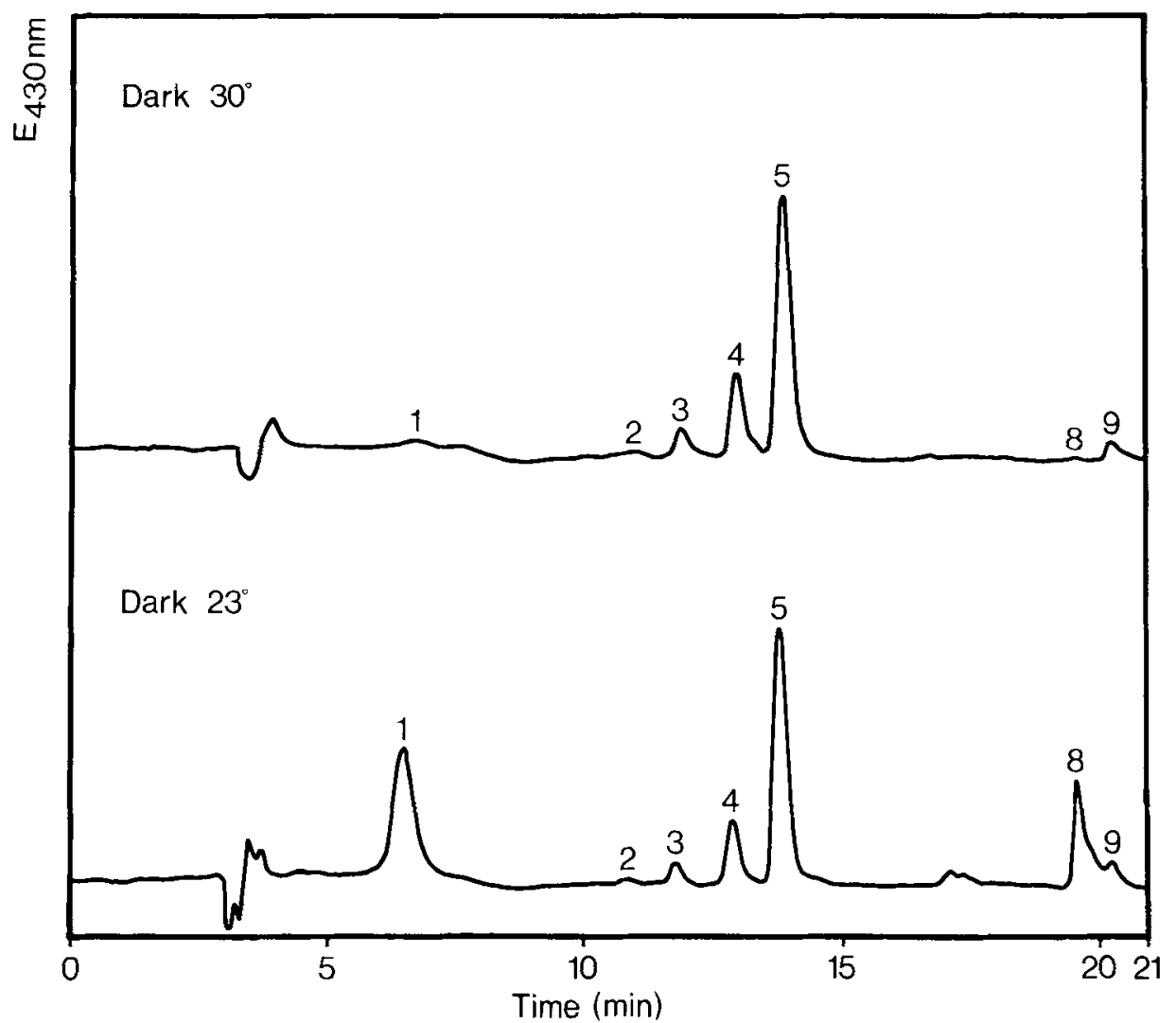

Figure 4: Elution profiles of pigments from tigrina-034 analyzed by HPLC.

The mutants were grown $A$. in the dark at either $30^{\circ} \mathrm{C}$ or $23^{\circ} \mathrm{C}$, and $B$. in white light $\left(55 \mu \mathrm{E} \cdot \mathrm{m}^{-2} \cdot \mathrm{sec}^{-1}\right)$ at either $23^{\circ} \mathrm{C}$ or $30^{\circ} \mathrm{C}$. The peaks were identified as 1 . protochlorophyllide, 2. neoxanthin, 3. violoxanthin, 4. monoepoxyxanthophyll, 5. lutein, 6 . chlorophyll $b, 7$. chlorophyll $a, 8$. lycopene, 9. $\beta$-carotene.

xanthophyll. Lutein epoxide and antheraxanthin, two monoepoxydihydroxyxanthophylls which have been reported to be present in etiolated barley (24) were not detected in these experiments. The quantitive analysis of the pigment content (Table II) showed that at $23^{\circ} \mathrm{C}$, the mutant had more total carotenes $(450 \%$ of wildtype levels) due to a large accumulation of lycopene, normal levels of $\beta$-carotene but decreased levels of the xanthophylls violaxanthin $(16 \%)$, neoxanthin $(50 \%)$, the unidentified epoxyxanthophyll (70\%) and lutein (85\%). The small amount of lycopene in the wild-type at $23^{\circ} \mathrm{C}$ is due to a selecting error. Therefore, in the dark the tigrina-o $0^{34}$ mutation was expressed more strongly at the lower temperature i.e. was cold-sensitive. In the dark the mutant gene tigrina-o 34 effected both an increased $\delta$-aminolevulinate and a de- creased xanthophyll formation. The latter was compensated by the accumulation of an equivalent amount of lycopene.

\subsection{The pigment composition of tigrina-0 34 and the wild-type grown under white light at $23^{\circ} \mathrm{C}$ and $30^{\circ} \mathrm{C}$}

As stated in the introduction, when tigrina-o $o^{34}$ was grown under constant light at the higher temperature of $30^{\circ} \mathrm{C}$ plastid structure and components more closely resembled the wild-type and chlorophyll content was increased compared to the lower growth temperature of $23^{\circ} \mathrm{C}$. Quantitive data are now presented which show that the increased amount of chlorophyll at the higher temperature was accompanied by an increased ratio of $\beta$-carotene to chlorophylls thus indicating a greater pigment stability. 


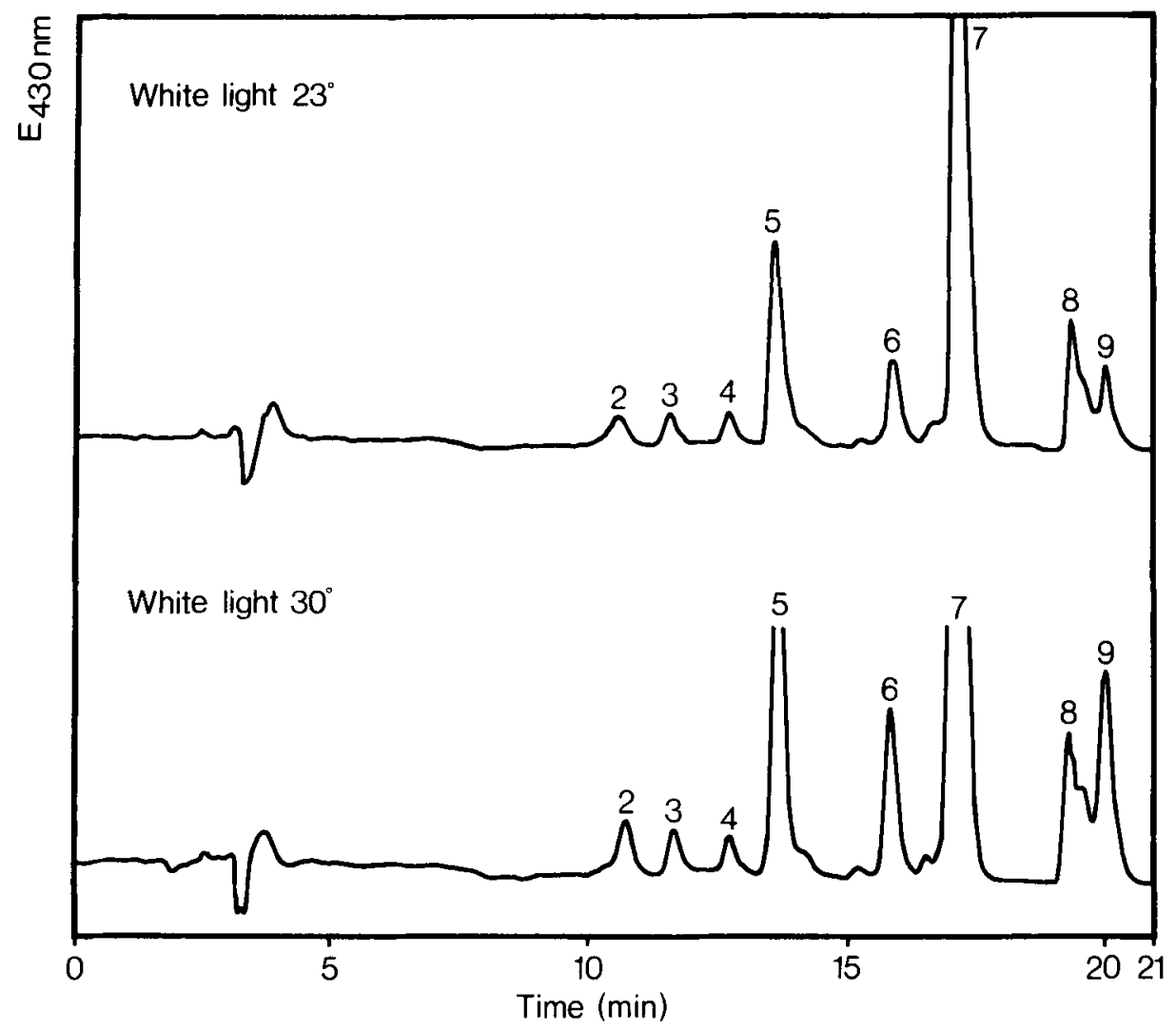

Figure 4B shows the separation by high pressure liquid chromatography of pigments from mutants seedlings grown under white light. The increased content of $\beta$-carotene (peak 9) at the high temperature is clearly seen. The mutant also contains at both temperatures a pigment (peak 4) (identified as an epoxyxanthophyll in section 3.1) which is absent in the wild-type. The quantitive pigment compositions in tigrina-o $o^{34}$ and wild-type at $23^{\circ} \mathrm{C}$ and $30^{\circ} \mathrm{C}$ are given in Table III. At $23^{\circ} \mathrm{C}$ compared to the wild-type the mutant had low levels of violoxanthin $(13 \%), \beta$ carotene $(19 \%)$, total carotenes $(61 \%)$ (of which accumulated lycopene represented $75 \%$ ), neo-

\section{Table I.}

Pigment content of single leaves from seedlings of genotypes tigrina-034/+ and tigrina-034/tigrina-0 34 grown in the dark at $30^{\circ} \mathrm{C}$.

\begin{tabular}{lccc}
\hline Pigment & \multicolumn{3}{c}{ Pigment content, nmoles per leaf } \\
\cline { 2 - 4 } & $\begin{array}{c}\text { average of six } \\
\text { tig-034/+ leaves }\end{array}$ & S.D. & $\begin{array}{c}\text { tig-o } \mathbf{3 4} \\
\text { leaf }\end{array}$ \\
\hline Protochlorophyllide & 0.12 & \pm 0.080 & 0.05 \\
Neoxanthin & 0.087 & \pm 0.049 & 0.15 \\
Violaxanthin & 0.17 & \pm 0.12 & 0.30 \\
Epoxyxanthophyll & 0.63 & \pm 0.19 & 0.72 \\
Lutein & 1.9 & \pm 0.52 & 1.8 \\
Lycopene & 0 & 0 & 0.1 \\
B-carotene & 0.16 & \pm 0.054 & 0.15 \\
\hline
\end{tabular}




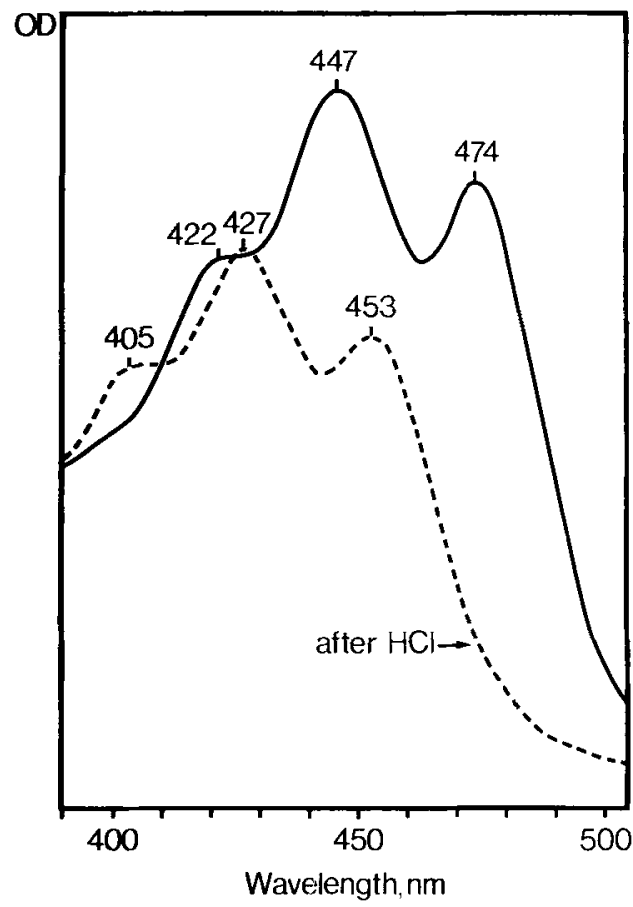

Figure 5. Absorption spectra of pigment in peak 4 .

The shift in absorption maxima upon the addition of $\mathrm{HCl}$ indicates that the pigment is a monoepoxycarotenoid.

xanthin (23\%) and lutein, chlorophyll $a$ and chlorophyll $b$ (all 28\%). The unidentified epoxyxanthophyll was also present in tigrina-o ${ }^{34}$ in amounts intermediate to those of neoxanthin and violoxanthin. Thus in contrast to the carotenoid content of the mutant in the dark at $23^{\circ} \mathrm{C}$, in the light there was a deficiency of $\beta$ carotene and of total carotenes in addition to the xanthophyll deficiency. This suggested that photodestruction of both $\beta$-carotene and lycopene were occurring.

At $30^{\circ} \mathrm{C}$ the levels of pigments in the mutant compared to the wild-type (beginning with the lowest levels ) were violoxanthin (29\%), chlorophyll $a(46 \%)$, neoxanthin (50\%), lutein (56\%), $\beta$-carotene (56\%), chlorophyll $b(60 \%)$ and total carotenes (144\%) of which lycopene represented $88 \%$.

When the pigment composition of the mutant at $23{ }^{\circ} \mathrm{C}$ was compared with its composition at $30{ }^{\circ} \mathrm{C}$ the largest increase was seen for $\beta$-carotene (160\%) followed by chlorophyll $b(60 \%)$, lutein $(50 \%)$, then chlorophyll $a(35 \%)$, violoxanthin $(30 \%)$ and the lowest in lycopene, the unidentified epoxyxanthophyll and neoxanthin (all 20$25 \%)$.

Therefore the pigment complement of the mutant resembled more closely the wild-type when grown at $30^{\circ} \mathrm{C}$ than at $23^{\circ} \mathrm{C}$. The relatively large increase in $\beta$-carotene content can be attributed to a better conversion of lycopene to $\beta$-carotene at the higher temperature. The conversion of lycopene to lutein also increased and more xanthophylls were formed from $\beta$-carotene. Abnormalities still occurring at $30^{\circ} \mathrm{C}$ in the mutant

Table II.

Pigment content of tigrina-a 34 and wild-type $\left(=t i g-0^{34} /+\right)$ grown at $23^{\circ} \mathrm{C}$ and $30^{\circ} \mathrm{C}$ in the dark for 7 days.

\begin{tabular}{lccc}
\hline Pigment & \multicolumn{3}{c}{ Content nmoles $\cdot \mathbf{g}^{-1}$ fresh weight } \\
\cline { 2 - 5 } & tigrina-0 34 & wild-type & $\begin{array}{c}1: 1 \text { mixture of } t i g-0^{34} \\
\text { and wild-type }\end{array}$ \\
\cline { 2 - 5 } & & $23^{\circ} \mathrm{C}$ & $30^{\circ} \mathrm{C}$ \\
\hline Protochlorophyllide & 9.6 & 0.9 & 1.3 \\
Neoxanthin & 0.9 & 1.8 & 1.1 \\
Violaxanthin & 1.2 & 7.7 & 2.2 \\
Epoxyxanthophyll & 5.3 & 7.4 & 7.6 \\
Lutein & 22 & 26 & 25 \\
Lycopene & 16 & 1.7 & 0.2 \\
3-carotene & 2.4 & 2.3 & 2.2 \\
Total xanthophylls & 29 & 43 & 36 \\
Total carotenes & 18 & 4 & 2.2 \\
\hline
\end{tabular}


Table III.

Pigment content of tigrina- $0^{34}$ and wild-type $(+/+)$ leaves grown in white light $\left(55 \mu \mathrm{E} \cdot \mathrm{m}^{-2} \cdot \mathrm{sec}^{-1}\right)$ at $23{ }^{\circ} \mathrm{C}$ and 30 ${ }^{\circ} \mathrm{C}$ for 7 days.

\begin{tabular}{lcccc}
\hline Pigment & \multicolumn{4}{c}{ Pigment content, nmoles $\cdot g^{-1}$ fresh weight } \\
\cline { 2 - 5 } & \multicolumn{3}{c}{ tigrina- $034^{34}$} & \multicolumn{3}{c}{ wild-type } \\
\cline { 2 - 5 } & $23^{\circ} \mathrm{C}$ & $30^{\circ} \mathrm{C}$ & $23^{\circ} \mathrm{C}$ & $30^{\circ} \mathrm{C}$ \\
\hline Neoxanthin & 9.6 & 12 & 41 & 24 \\
Violaxanthin & 4.3 & 5.5 & 32 & 19 \\
Epoxyxanthophyll & 6.5 & 7.8 & 0 & 0 \\
Lutein & 37 & 55 & 130 & 97 \\
Chlorophyll $b$ & 62 & 99 & 219 & 165 \\
Chlorophyll $a$ & 200 & 270 & 710 & 590 \\
Lycopene & 47 & 56 & 0 & 0 \\
$\beta$-carotene & 14 & 36 & 75 & 64 \\
Total xanthophylls & 57 & 80 & 200 & 140 \\
Total carotenes & 61 & 92 & 75 & 64 \\
Carotene/xanthophyll & 1.1 & 1.1 & 0.38 & 0.46 \\
B-carotene/chlorophyll & 0.05 & 0.09 & 0.08 & 0.08 \\
\hline
\end{tabular}

were the occurrence of the unidentified epoxyxanthophyll, a low violoxanthin/chlorophyll ratio and a continued lycopene accumulation. At the higher temperature there was a partial reversal of the cold-sensitive lesion affecting $\beta$-carotene formation from lycopene. Consequently, the ratio of $\beta$-carotene to chlorophylls in tigrina$o^{34}$ increased from 0.05 at $23{ }^{\circ} \mathrm{C}$ to wild-type levels of 0.09 at $30^{\circ} \mathrm{C}$. The increased content of $\beta$-carotene and xanthophylls stabilised a larger amount of chlorophylls.

In white light the cold-sensitive carotenoid deficiency caused photoinstability and was associated with chlorophyll deficiency. It therefore might be expected that if tigrina-o $o^{34}$ was grown at the lower temperature but at light intensities and qualities where photodestruction would be lessened, an increase in chlorophyll content and plastid stability is to be seen.

\subsection{The pigment composition of tigrina-0 $0^{34}$ and wild-type leaves grown at $23{ }^{\circ} \mathrm{C}$ under $>600 \mathrm{~nm}$ and $>650 \mathrm{~nm}$ red light}

To test the effect of light intensity and quality seedlings were grown under two light sources differing in intensity and quality. These were $>600 \mathrm{~nm}$ red light $\left(20 \mu \mathrm{E} \cdot \mathrm{m}^{-2} \cdot \mathrm{sec}^{-1}\right)$ and $>650 \mathrm{~nm}$ red light $\left(1.4 \mu \mathrm{E} \cdot \mathrm{m}^{-2} \cdot \mathrm{sec}^{-1}\right)$. The lowest intensity light $(>650 \mathrm{~nm}$ red light $)$ was of a quality (Figure 3) such that any non-photoactive protochlorophyllide, with an absorption maximum at $635 \mathrm{~nm}$, that might accumulate, would not absorb the light and would not act as a photosensitiser. As shown in Table IV protochlorophyllide was detected in tigrina-o $o^{34}$ and the wild-type grown under the lower intensity $>650 \mathrm{~nm}$ red light in amounts similar to those found in dark grown wild-type (section 3.1). This suggests that the light intensity was low enough to limit photoconversion of protochlorophyllide and thus chlorophyll formation. The similarity of the chlorophyll content of the wild-type controls under the $>600 \mathrm{~nm}$ red light and white light (section 3.2) indicated that chlorophyll formation under $>600 \mathrm{~nm}$ red light was not limited by light intensity. Pigment levels in the mutant grown under $>600$ and $>650 \mathrm{~nm}$ red light as a percentage of the comparable wild-type levels, were respectively for violoxanthin $(18 \%$ and $12 \%)$, for $\beta$-carotene $(14 \%, 31 \%)$, lutein $(25 \%$, $29 \%)$, neoxanthin $(28 \%, 22 \%)$, chlorophyll $a$ $(26 \%, 54 \%)$ chlorophyll $b(32 \%, 43 \%)$ total carotenes $(79 \%, 172 \%)$ of which lycopene represented $63 \%$ and $138 \%$. Larger amounts of the unidentified epoxyxanthophyll eluting in peak 4 (see Figure 4) was present in the mutants grown under $>650 \mathrm{~nm}$ red light than under $600 \mathrm{~nm}$ red light. It could be an unknown intermediate of 
Table IV.

Pigment content of tigrina-o34 and wild-type grown for 7 days under $>600 \mathrm{~nm}\left(20 \mu \mathrm{E} \cdot \mathrm{m}^{-2} \cdot \mathrm{sec}^{-1}\right)$ or $>650 \mathrm{~nm}(1.4$ $\left.\mu \mathrm{E} \cdot \mathrm{m}^{-2} \cdot \sec ^{-1}\right)$ red light at $23^{\circ} \mathrm{C}$. ND, not determined.

\begin{tabular}{|c|c|c|c|c|}
\hline \multirow[t]{3}{*}{ Pigment } & \multicolumn{4}{|c|}{ Content nmoles $\cdot \mathrm{g}^{-1}$ fresh weight } \\
\hline & \multicolumn{2}{|c|}{ tigrina-o 34} & \multicolumn{2}{|c|}{ wild-type } \\
\hline & Red $>600 \mathrm{~nm}$ & Red $>650 \mathrm{~nm}$ & Red $>600 \mathrm{~nm}$ & Red $>650 \mathrm{~nm}$ \\
\hline Protochlorophyllide & ND & 1.8 & ND & 1.1 \\
\hline Neoxanthin & 8.2 & 4.4 & 29 & 20 \\
\hline Violaxanthin & 4.1 & 2.8 & 23 & 23 \\
\hline Epoxyxanthophyll & 5.9 & 7.9 & 0 & 0 \\
\hline Lutein & 25 & 19 & 100 & 65 \\
\hline Chlorophyll $b$ & 28 & 40 & 87 & 94 \\
\hline Chlorophyll $a$ & 160 & 150 & 620 & 280 \\
\hline Lycopene & 45 & 64 & 0 & 0 \\
\hline$\beta$-carotene & 8.8 & 17 & 64 & 47 \\
\hline Total xanthophyll & 43 & 34 & 150 & 111 \\
\hline Carotenes & 54 & 81 & 68 & 47 \\
\hline Carotene/xanthophyll & 1.3 & 2.4 & 0.43 & 0.42 \\
\hline$\beta$-carotene/chlorophyll & 0.04 & 0.08 & 0.09 & 0.12 \\
\hline
\end{tabular}

xanthophyll biosynthesis. In the wild-type grown under $>650 \mathrm{~nm}$ red light pigments eluted in peak 4. Their spectra, however, suggested that they could be a mixture of antheraxanthin and lutein epoxide. In the mutant, $\beta$-carotene to chlorophyll ratios under the $>600 \mathrm{~nm}$ red light $(0.04)$ were appreciably decreased compared to the ratio $(0.08)$ present in seedlings grown under the red light of lower intensity $(>650 \mathrm{~nm}$ ) (Table IV).

In the light the phenotype of tigrina-o 34 tended toward normality either when grown at $30{ }^{\circ} \mathrm{C}$ under white light or under $>650 \mathrm{~nm}$ red light at $23{ }^{\circ} \mathrm{C}$. Could tigrina-o34 be completely normalised by growth at $30^{\circ} \mathrm{C}$ under $>650 \mathrm{~nm}$ red light? Figure $2 \mathrm{E}$ shows that leaves from tigrina$o^{34}$ and wild-type grown under these conditions could not be distinguished by their pigment content. Lycopene and chlorophyll $a_{743}$ were not detected in these plants. However, testing sixteen single leaves for their ability to fix $\mathrm{CO}_{2}$ under high light intensitiy revealed two classes of leaves. Ten had a low activity of $\mathrm{CO}_{2}$ fixation (50-100 $\times 10^{3} \mathrm{cpm}$ leaf -1$)$ similar to wild-type in the dark $\left(87 \times 10^{3} \mathrm{cpm}\right.$ leaf- -1$)$. The other six leaves showed high $\mathrm{CO}_{2}$ fixation $\left(120-240 \times 10^{3} \mathrm{cpm}^{-1 e a f-1}\right)$, indicating the ability to photosynthesize. Since tigrina-o ${ }^{34}$ segregates 1:1 we consider the homozygous mutants unable to fix $\mathrm{CO}_{2}$ even though they appear normal. These results imply that although the pigment composition of tigrina-o ${ }^{34}$ resembled the wild-type when both were grown at $30^{\circ} \mathrm{C}$ under $>650 \mathrm{~nm}$ red light the primary defect in this mutant remained and was not overcome by these conditions.

\subsection{The accumulation of chlorophyll $a_{743}$ in tigrina-0 $0^{34}$ grown in the light}

The defective formation of $\beta$-carotene from lycopene at lower temperatures in tigrina-o $0^{34}$ can also be related to another phenomenon observed in light grown mutants, i.e. the accumulation of chlorophyll $a_{743}$. In tigrina-o $0^{34}$ the accumulation of an abnormal form of chlorophyll $a$, having an absorption maximum at $743 \mathrm{~nm}$ in the leaf, has been shown to be much more pronounced at a lower growth temperature $\left(20^{\circ} \mathrm{C}\right)$ than at a higher one $\left(30^{\circ} \mathrm{C}\right)(28)$. Mutants grown at low light intensities such as in $>650 \mathrm{~nm}$ red light studied in this paper also accumulated chlorophyll $a_{743}$. As shown in Figure 6 thylakoids isolated from the top half of the mutant leaf contained more chlorophyll $a_{743}$ relative to chlorophyll $a_{678}$ than thylakoids from the bottom half. Significantly the top half of the mutant leaf also contained the greatest amount of lycopene, representing the excess carotenes accumulated by tigrina-o ${ }^{34}$ compared to the wild- 


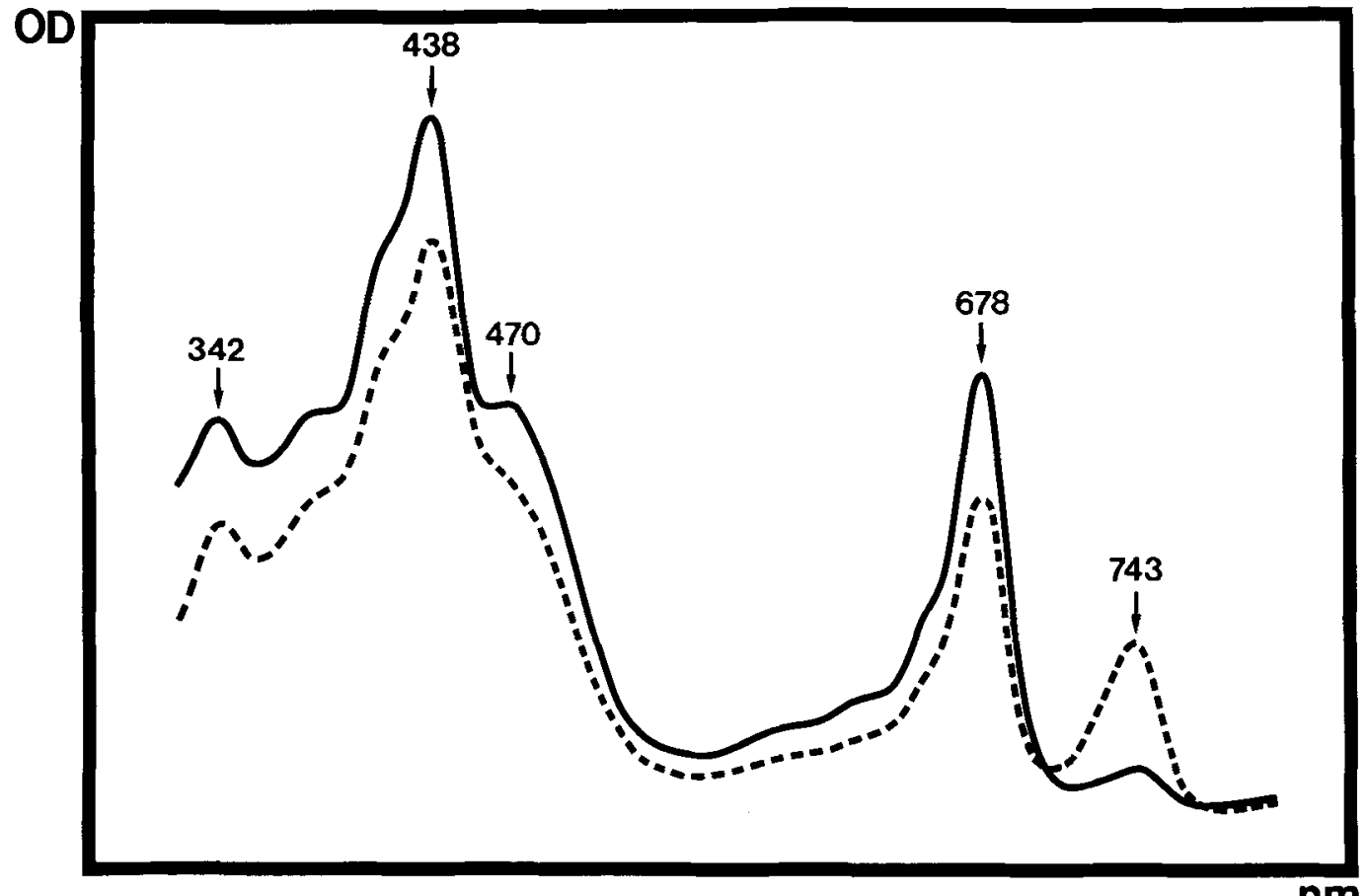

$\mathbf{n m}$

Figure 6. Absorption spectra of purified thylakoids isolated from the bottom half (-), and the top half (- - - -) of a tigrina-o 34 leaf grown in continuous $>650 \mathrm{~nm}$ red light at $23^{\circ} \mathrm{C}$.

type control. As will be shown in section 3.7 a thylakoid membrane preparation of the mutant contained chlorophyll $a_{743}$ in association with lycopene. The abnormal absorption maximum of the chlorophyll at $743 \mathrm{~nm}$ must be due to an aberrant organisation of the chlorophyll molecules in the membranes.

Figure 7 illustrates that tigrina-o 34 leaves grown in white light at $23^{\circ} \mathrm{C}$ did not have the large wildtype fluorescence emission peak at $740 \mathrm{~nm}$. Instead a small fluorescence emission maximum at a wavelength slightly higher than $743 \mathrm{~nm}$ was seen, but the size of this emission maximum was not proportional to the amount of chlorophyll $a_{743}$ present in leaves of tigrina-o ${ }^{34}$ under these conditions (28). This provides evidence that chlorophyll $a_{743}$ represents aggregates of chlorophyll which will be analysed in section 3.7.

\subsection{Ribosome content of tigrina-o 34 grown in the dark and in red light at $23^{\circ} \mathrm{C}$}

It was previously suggested that the loss of $70 \mathrm{~S}$ ribosomes in tigrina-o $o^{34}$ grown at $20^{\circ} \mathrm{C}$ in the light could be explained by the abnormal carotenoid composition and consequent pho- toinstability of these ribosomes (17). As shown below this explanation was supported by the finding of a normal $70 \mathrm{~S}$ ribosome complement in mutants grown in the dark and under low in-

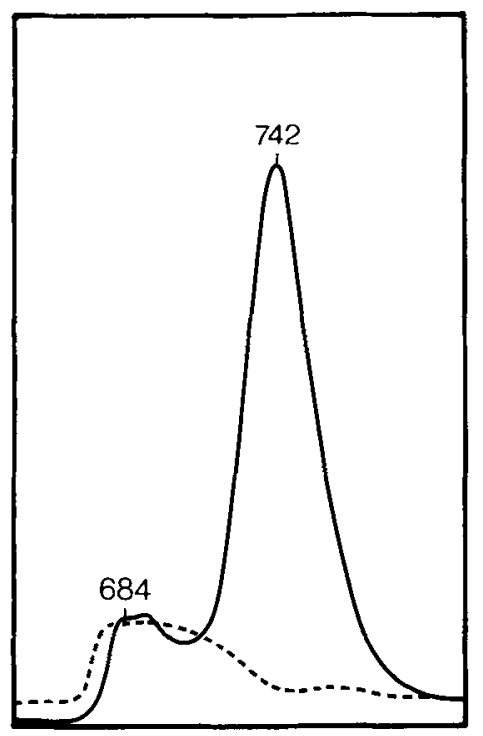

Figure 7. The fluorescence emission spectra in liquid nitrogen of wild-type (-) and tigrina-o34 (-...) leaves grown in white light $\left(55 \mu \mathrm{E} \cdot \mathrm{m}^{-2} \cdot \mathrm{sec}^{-1}\right)$ at $23^{\circ} \mathrm{C}$. 

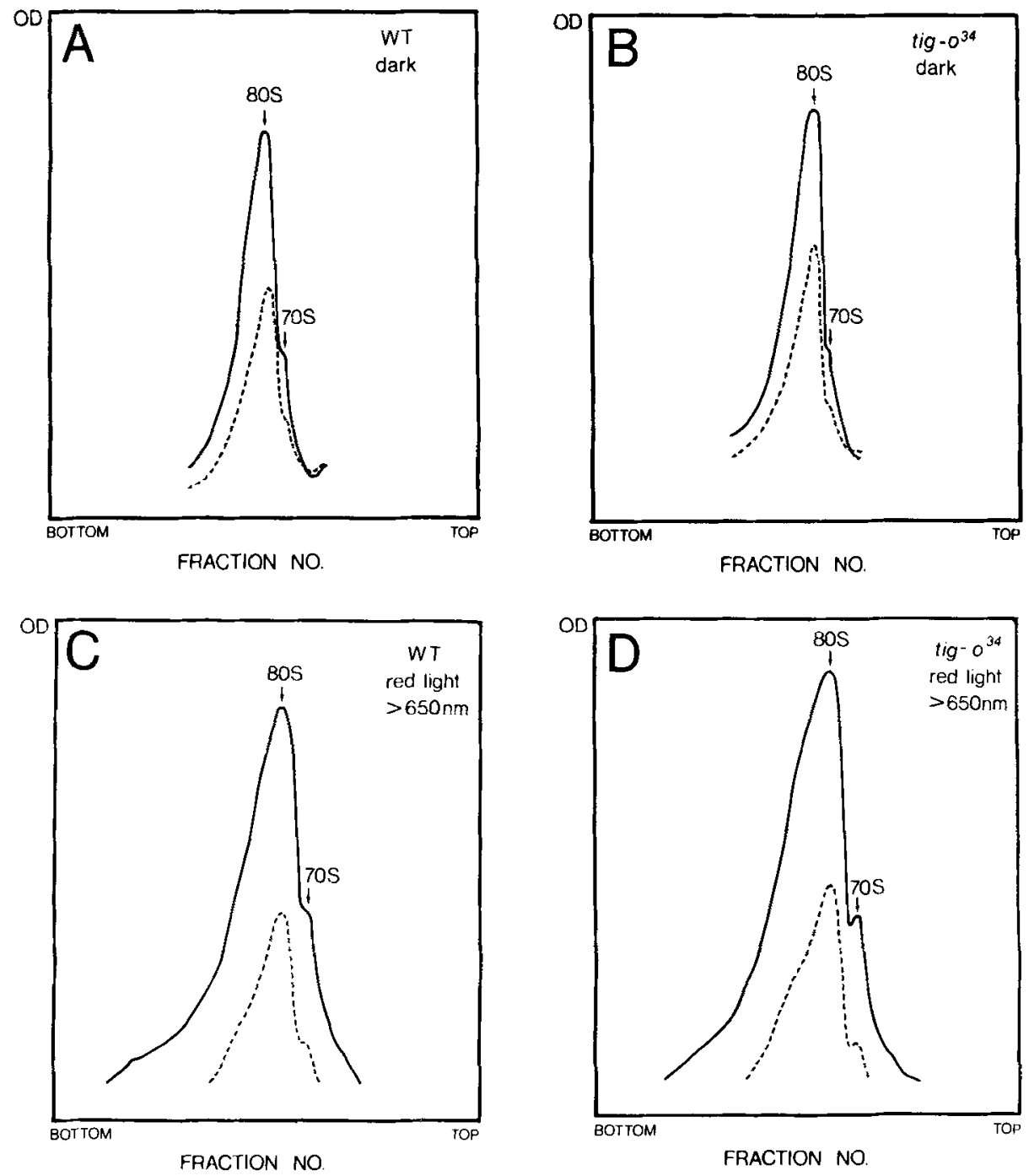

Figure 8. Separation of $70 \mathrm{~S}$ and $80 \mathrm{~S}$ ribosomes from wild-type and tigrina-0 ${ }^{34}$ on $10-30 \%$ sucrose gradients.

Wild-type and the mutant were grown $(A, B)$ in the dark at $23^{\circ} \mathrm{C},(C, D)$ in $>650 \mathrm{~nm}$ and $(E)$ in $>600 \mathrm{~nm}$ red light. In each experiment $5 \mathrm{OD}_{260}$ units of crude ribosomes were applied. The gradients were tapped from the top and $\mathrm{OD}_{260}(-)$ and $\mathrm{OD}_{280}(-\cdot-)$ were monitored continuously. The ribosomal peaks were identified by their position in the gradient and characteristic polypeptide patterns on SDS-PAGE.

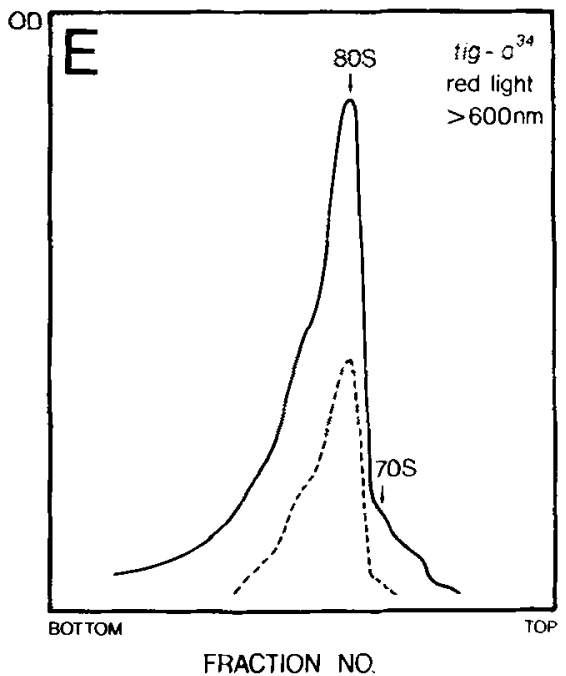


tensity $>650 \mathrm{~nm}$ red light. Figure $8 \mathrm{~A}$ and $\mathrm{B}$ shows the separation of 80 and $70 S$ ribosomes from etiolated wild-type and tigrina-o $o^{34}$, respectively. The $70 \mathrm{~S}$ ribosomes from the etiolated plants are seen as a shoulder on the $80 \mathrm{~S}$ peak. Chloroplast ribosomes are present in dark-grown mutant seedlings in amounts comparable to those of the wild-type. The photoinstability of the plastid ribosomes is demonstrated by their presence in the mutant grown in the dark at $23^{\circ} \mathrm{C}$ and their deficiency in mutants grown at a similar temperature in white light (17).

As expected, at $23^{\circ} \mathrm{C}$, the chloroplast ribosomes were also more stable under the lower intensity $>650 \mathrm{~nm}$ red light than under the more intense $>600 \mathrm{~nm}$ red light. Figures $8 \mathrm{C}$ and D show the sucrose gradient separation of cytoplasmic (80S) and chloroplast ribosomes from wild-type and tigrina-o ${ }^{34}$ grown in $>650 \mathrm{~nm}$ red light. The amount of $70 \mathrm{~S}$ ribosomes in the two cases are comparable showing that when grown under the low intensity $>650 \mathrm{~nm}$ red light the mutant is not deficient in chloroplast ribosomes. When the mutant is grown under $>600 \mathrm{~nm}$ red light the content of chloroplast ribosomes is decreased (Figure 8E). So, whereas the $70 S$ chloroplast ribosomes were unstable when tigrina-o $o^{34}$ was grown under $>600 \mathrm{~nm}$ red light at $23{ }^{\circ} \mathrm{C}$, they were stable under the lower intensity $>650 \mathrm{~nm}$ red light at the same temperature.

In order to determine whether the chloroplast ribosomes from mutants grown under $>650 \mathrm{~nm}$ red light had a normal polypeptide composition the isolated $70 \mathrm{~S}$ ribosomes were subjected to SDS-PAGE analysis. Polypeptide patterns of $70 \mathrm{~S}$ ribosomes from wild-type and tigrina-o $a^{34}$ grown in $>650 \mathrm{~nm}$ red light were identical, as judged by the limited resolution of one-dimensional SDSPAGE (Figure 9).

\subsection{The thylakoid polypeptide composition of tigrinz-0 34 grown at $23{ }^{\circ} \mathrm{C}$ under $650 \mathrm{~nm}$ and $600 \mathrm{~nm}$ red light and in the dark}

The thylakoid polypeptide composition as determined by PAGE in SDS of the mutant grown at $23{ }^{\circ} \mathrm{C}$ cannot be simply reconciled with the observed stability or instability of the chloroplast ribosomes under the different growth conditions. As shown below, membrane polypeptides

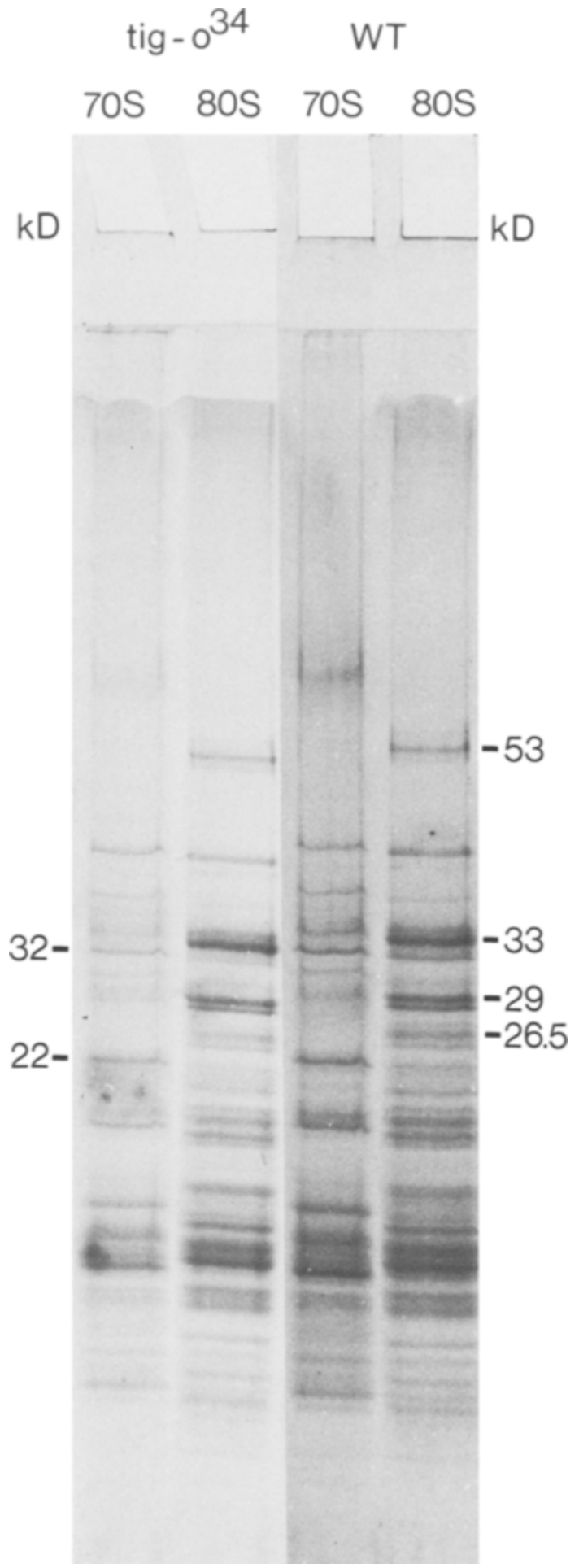

Figure 9. The polypeptide pattern of $70 \mathrm{~S}$ and $80 \mathrm{~S}$ ribosomal proteins from tigrina-o 34 and the wild-type grown in $>650 \mathrm{~nm}$ red light at $23^{\circ} \mathrm{C}$. 


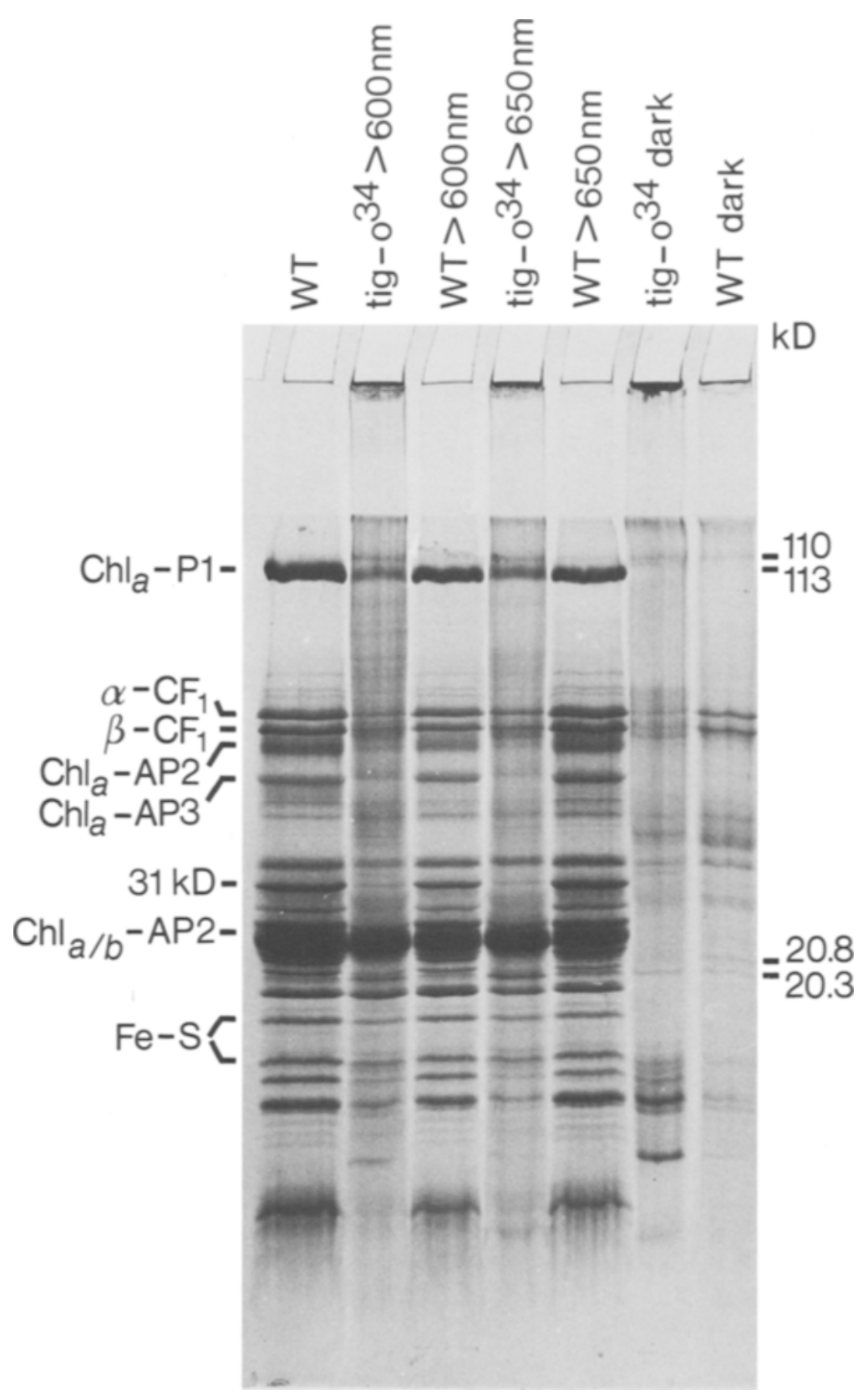

Figure 10. Thylakoid polypeptide pattern of wild-type and tigrina-o34 grown in the dark and in red light at $23^{\circ} \mathrm{C}$. The wild-type control was grown in white light $\left(55 \mu \mathrm{E} \cdot \mathrm{m}^{-2} \cdot \mathrm{sec}^{-1}\right)$. In lanes $1-5 \mathrm{appr} .25 \mu \mathrm{g}$ of chlorophyll was applied.

known to be synthesised in the plastid are deficient where the presence of normal amounts of $70 \mathrm{~S}$ ribosomes would suggest that such polypeptides could be formed. It is also shown in this section that the unusual chlorophyll $a_{743}$ is present in the thylakoid membrane preparation from mutants but does not enter the gel.

In tigrina-o ${ }^{34}$, grown under the lower intensity 
$>650 \mathrm{~nm}$ red light, compared to the wild-type, the prominently reduced membrane polypeptides were chlorophyll $a$ proteins 1,2 and 3 , the $\alpha$ and $\beta$ subunits of $C F_{1}$ and a $31 \mathrm{kD}$ polypeptide (Figure 10). These are all synthesised on chloroplast ribosomes. A similar reduction was seen in mutants grown under the higher intensity $>600 \mathrm{~nm}$ red light where chloroplast ribosomes were deficient. Thus at $23{ }^{\circ} \mathrm{C}$ even when $70 \mathrm{~S}$ ribosomes are present in tigrina-o ${ }^{34}$, they are either not very active in the synthesis of thylakoid polypeptides or the polypeptides synthesised on these ribosomes are not inserted into the membranes. In contrast to the deficiencies of the membrane polypeptides known to be synthesised on chloroplast ribosomes, relatively large amounts of chlorophyll $a / b$-protein 2 synthesised on cytoplasmic ribosomes were found in the membranes of mutants grown under both red lights.

As has been shown, chloroplast ribosomes are present in normal amounts in dark grown tigrina-o ${ }^{34}$ grown at $23^{\circ} \mathrm{C}$ and the polypeptide composition of the isolated internal plastid membranes is qualitatively similar to that of the wildtype. However, just as in plastids grown under $>650 \mathrm{~nm}$ red light, plastid membranes from dark grown mutants contained fewer of the plastid synthesized polypeptides than the wild-type as especially noticable for the $\alpha$ and $\beta$ subunits of coupling factor, $\mathrm{CF}_{\mathrm{l}}$. This deficiency has been previously noted (12) and may be due to assembly difficulties on the abnormal membranes. The prominent low molecular weight bands (Figure 10) in the pattern from etiolated mutant membranes were due to contamination with material of nuclear origin (18). This and the low yields of internal membranes from etiolated tigrina-o $o^{34}$ seedlings may be attributed to the freezing in liquid nitrogen used for identification of the mutants.

Considerable differences between the polypeptide patterns of tigrina-034 and the wild-type were observed in dark and light grown seedlings. The $113 \mathrm{kD}$ polypeptide, present in equal amounts in mutant and wild-type etioplast membranes, disappeared in the wild-type but not in the mutant as the light intensity was increased. The presence of this polypeptide in mutants grown in the light is one of the signs of impaired development from etioplast to functional chloroplast. A $20.8 \mathrm{kD}$ polypeptide was present in relatively minor amounts in wild-type etioplasts and almost absent in the mutant but was progressively increased in both in brighter light. The amount of this polypeptide was always less in the mutant. A $20.3 \mathrm{kD}$ polypeptide present in equal amounts in wild-type and mutant etioplasts, was present in increased amounts under the lowest intensity $>650 \mathrm{~nm}$ red light but decreased in brighter light. In the light the mutant had greater amounts of this polypeptide than the wild-type. The significance of these observations is not apparent at the present time.

Chlorophyll $a_{743}$ could be identified on the gels after electrophoresis. In Figure 10 it can be seen that a relatively large amount of material fails to enter the gel in all tracks of mutant material. For light grown mutants this material was identified as the abnormal chlorophyll $a_{743}$ found in leaves of tigrina-034. This chlorophyll $a_{743}$ was present in the SDS treated mutant thylakoids applied to the gel but did not penetrate the gel during electrophoresis. The abnormal chlorophyll remained as an orange-green precipitate at the top of the gel during electrophoresis and could be stained with Coomassie Blue after electrophoresis indicating the presence of some protein. This portion of the gel and all the chlorophyll containing bands were cut out after electrophoresis and analysed in the spectrophotometer. Chlorophyll $a_{743}$ was found only in the precipitate that did not enter the gel. Pigments were extracted from the precipitate. The gel was ground in liquid nitrogen, extracted with acetone and pigments separated by chromatography revealing chlorophyll $a$ and lycopene as the main pigments. Trace amounts of chlorophyll $b$ were also present. Chlorophyll $a_{743}$ is therefore an aggregated form of chlorophyll $a$ which is bound to lycopene together with some unidentified protein or proteins which under the circumstances are not soluble in SDS.

The relative amounts of membrane polypeptides in the top and bottom half of mutant leaves grown under $>650 \mathrm{~nm}$ red light was determined so that they could be compared with the distribution of chlorophyll $a_{743}$ and of structural features seen under the electron microscope which are 


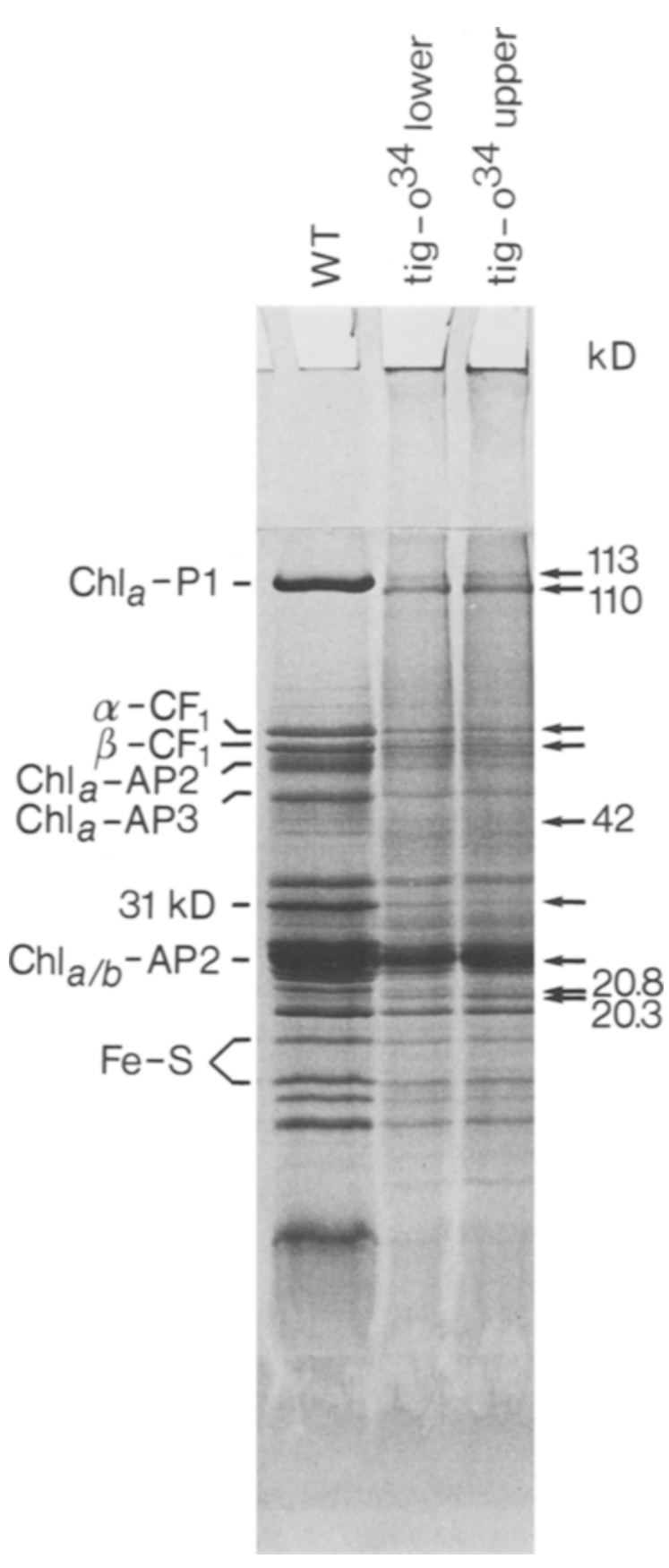

Figure 11. Polypeptide pattern of thylakoids isolated from the apical and the basal part of the mutant leaf grown in $>650 \mathrm{~nm}$ red light. The wild-type was grown in white light $\left(55 \mu \mathrm{E} \cdot \mathrm{m}^{-2} \cdot \mathrm{sec}^{-1}\right)$. reported in the next section. The polypeptide composition of thylakoids from the upper and lower parts of the primary leaf was determined as follows. Mutants were cut approximately at level 4 (Figure 12) and thylakoids were isolated, purified and analyzed by SDS-PAGE. Figure 11 shows that there are differences in the thylakoid polypeptide composition of plastids from the upper and lower parts of the mutant leaf. More chlorophyll $a / b$-protein 2 , synthesised on cytoplasmic ribosomes was found in the upper part of the leaf, where chlorophyll $a_{743}$ is abundant. The chloroplast coded, $\alpha$ and $\beta$ subunits of $\mathrm{CF}_{\mathrm{l}}$, and the chlorophyll $a$-proteins 1, 2 and 3, were present in equal amounts in thylakoids isolated from the top and bottom parts of the leaf whereas there was a relative deficiency of a $31 \mathrm{kD}$ polypeptide in the upper part of the leaf. This indicates that the chloroplastic ribosomes are more active in thylakoid polypeptide synthesis in younger than in older mutant plastids. The 20.8 $\mathrm{kD}$ and $42 \mathrm{kD}$ polypeptides are absent in older plastids, whereas the amount of the $20.3 \mathrm{kD}$ polypeptide is increased.

Altogether these results show that there is a relative deficiency of certain membrane polypeptides in plastid membranes from tigrina-o 34 grown at $23{ }^{\circ} \mathrm{C}$. This deficiency is not due to photodestruction of chloroplast ribosomes.

\subsection{Plastid membrane structure of tigrina-034 grown at $23{ }^{\circ} \mathrm{C}$ in the dark and in red light}

In order to study the development of stuctural irregularities in tigrina- $o^{34}$ and relate them to the abnormal pigment content the etioplast and chloroplast structures were examined along the primary leaf from the youngest tissue (level 1) to the oldest (level 6), as illustrated in Figure 12.

In the dark grown tigrina-o ${ }^{34}$ plastid, at level 1 , the proplastids contain few internal membranes (Figure 13). At levels 2 and 3 where the plastids are more mature there is an increased but similar amount of membranes (Figures 14 and 15). The membranes were in places arranged into prolamellar bodies without paracrystalline structure and ribosomes were visible in these plastids. A further increase in the amount of internal membranes was found in the plastids of level 4 and regions of appressed primary lamellar layers were seen (Figure 16). Typical prolamellar bodies 
with paracrystalline structures were visible in the etioplasts at level 5 (Figure 17) and 6 (Figure 18). In these older plastids few membranes radiating from the prolamellar bodies were seen and most of the membranes were appressed into some very electron-dense structures resembling tightly packed grana (e.g. Figure 17, arrow). Undulating osmiophilic sheets were also seen (Figure 18, arrows). All of these electron dense structures can be attributed to the excess amounts of carotene represented by lycopene and the deficiency of xanthophylls, seen in dark grown tigrina-o ${ }^{34}$ (section 3.1).

In plastids of the mutant grown in white light at the same temperature ribosomes were not detected above level 2 (17) but plastid ribosomes were clearly visible at all levels of the primary

Figure 12. Positions along the primary leaf where samples for electron microscopy were collected.

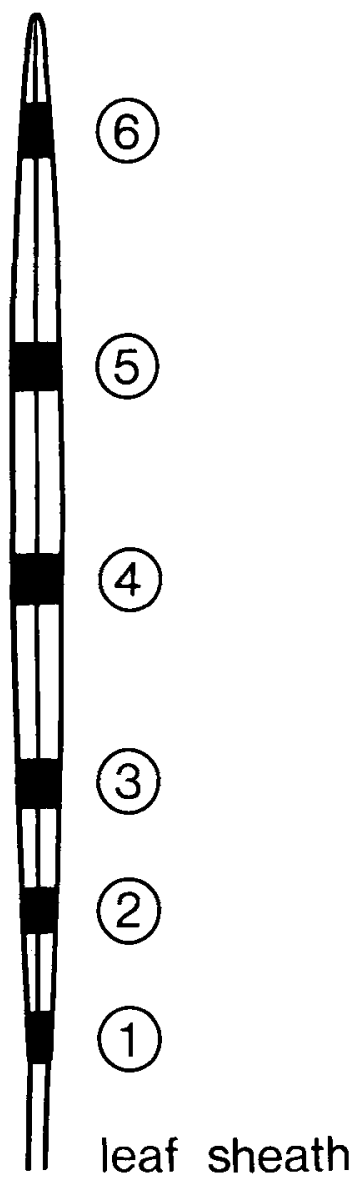

leaf of tigrina-o ${ }^{34}$ grown at $23^{\circ} \mathrm{C}$ in the dark. This indicated that the absence of plastid ribosomes in tigrina-o $0^{34}$ in white light at $23{ }^{\circ} \mathrm{C}$ was due to photodestruction.

In order to relate the deficiency of the pigment composition and $70 \mathrm{~S}$ ribosomes in tigrina- $0^{34}$ with changes occurring in the plastid ultrastructure, plants grown under $>600 \mathrm{~nm}$ and $>650 \mathrm{~nm}$ red light were studied by electron microscopy. The ultrastructure of the plastids in the wild-type leaf at levels representing the different ages are presented first and then compared with the structures in the mutant leaf. In wild-type seedlings grown under $>650 \mathrm{~nm}$ red light (where the mutant plastid is more stable) very young plastids at level 1 contained few internal membranes (Figure 19). Both prolamellar bodies and small membrane stacks were present in these plastids. An increase in the amount of internal membranes were seen in plastids at level 2 (Figure 20). Large paracrystalline prolamellar bodies were usually interconnected with a well-developed thylakoid system. This contemporary presence of prolamellar bodies, grana and intergrana membranes in plants grown under low light intensity has previously been described (16). In plants grown under $>650 \mathrm{~nm}$ red light this system of membranes was found throughout the primary leaf. However, towards the tip of the leaf, the prolamellar bodies accounted for smaller and smaller amounts of the total membranes. At level 6 most of the plastid internal membranes were arranged into grana and intergrana lamellae, although some prolamellar bodies were still present (Figure 21).

In the mutant the development of the plastids under the $>650 \mathrm{~nm}$ red light was comparable to the wild-type up to level 4 (Figures 22, 23 and 24). Both normal and abnormal plastids were observed at level 4 (Figure 25). Prolamellar bodies were still present. In the aberrant plastids prolamellar bodies seemed to account for most of the normal membranes which remained (Figure 26). Very electron-dense large membrane stacks were visible, sometimes interconnected with the prolamellar bodies (Figure 26, arrow). Undulating osmiophilic sheets were seen in the aberrant plastids (Figure 26, double arrow). At level 5 all plastids were abnormal (Figure 27). Their internal membranes were arranged either 

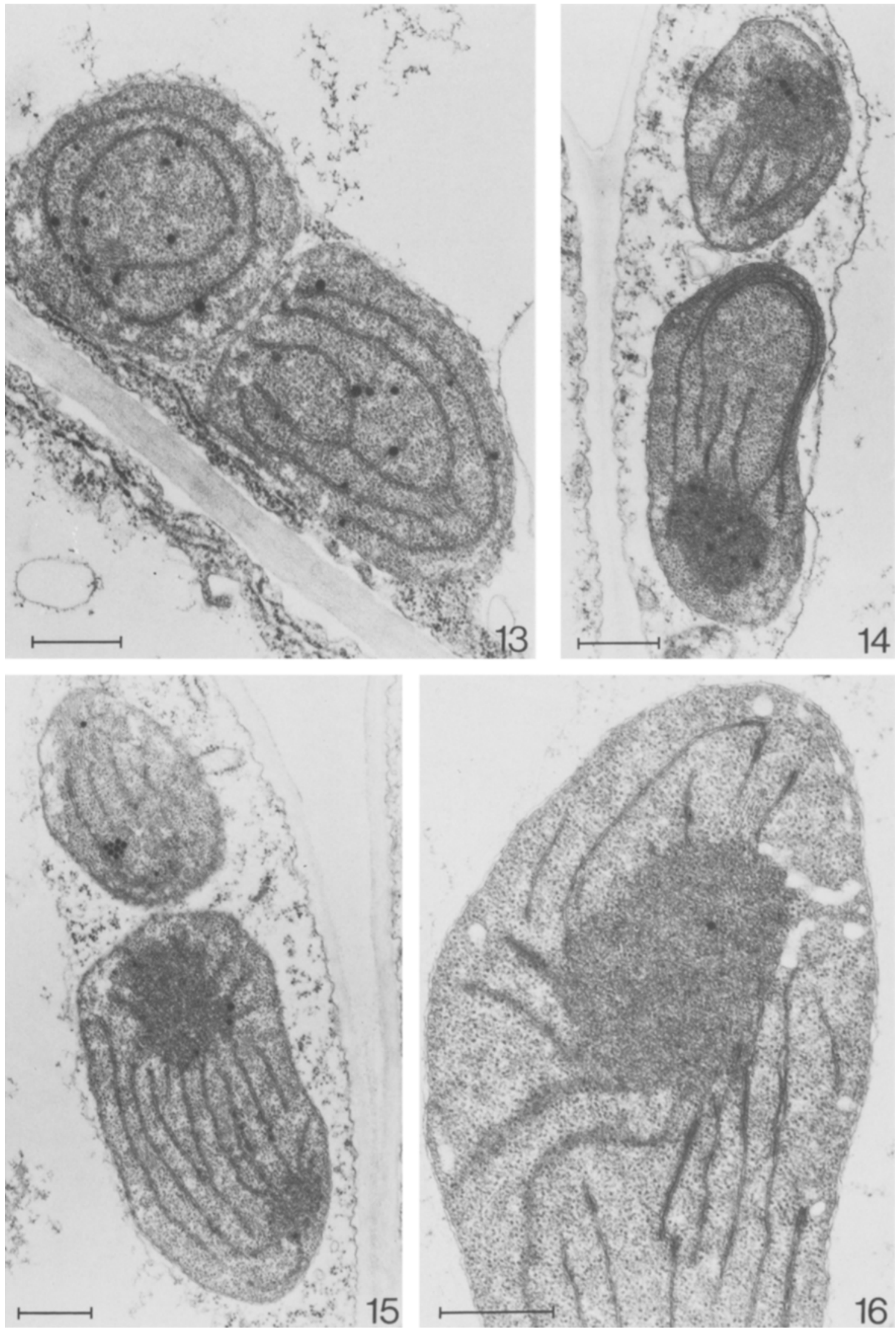
4 Figures 13 to 16 . The tigrina-o34 mutant grown in the dark at $23^{\circ} \mathrm{C}$.

Figures $13,14,15$ and 16 show plastids of increasing age from levels 1, 2, 3 and 4, respectively, and the corresponding increase in amount of internal membranes. Ribosomes are clearly visible inside all the plasiids. ( $\mathrm{Bar}=0.5 \mu \mathrm{m})$.

as very electron-dense stacks (Figure 27, arrows) or as prolamellar bodies. Ribosomes were present inside these plastids as well as inside the plastids of level 6 . At this level the prolamellar bodies were very small and the plastid stroma showed some vacuolation (Figure 28 ) indicating plastid destruction. The electron-dense stacks and the undulating osmiophilic membranes (Figures 27 and 28) may be derived, respectively, by the selfcondensation of grana and of intergranal membranes (Figure 24).

The electron-dense stacks found in tigrina-o 34 have been freeze-fractured and found to contain, on the PFs face, hexagonally packed particles with a $100 \AA$ repeat (34). When purified lightharvesting chlorophyll $a / b$-protein containing mainly chlorophyll $a / b$-protein 2 was freeze-fractured, the fracture face was found to contain hexagonally arrayed particles with an average centre-to-centre distance of $122 \dot{A}$. Similar size particles were absent from the PFs face of the mutant chlorina- 2 which lacks the chlorophyll $a /$ $b$-protein 2 (31). This strongly indicates that the large amounts of chlorophyll $a / b$-protein 2 found

Figures $17 \& 18$. The tigrina-0 34 mutant grown in the dark at $23^{\circ} \mathrm{C}$.

Figures 17 and 18 show plastids characteristic for levels 5 and 6 , respectively. At both levels paracrystalline prolamellar bodies are seen. Very electrondense membrane stacks (arrows) and undulating osmiophilic sheets, typical for lycopene accumulations (Figure 18, double arrow) are seen. Plastid ribosomes are clearly recognizable $(\mathrm{Bar}=0.5 \mu \mathrm{m})$.
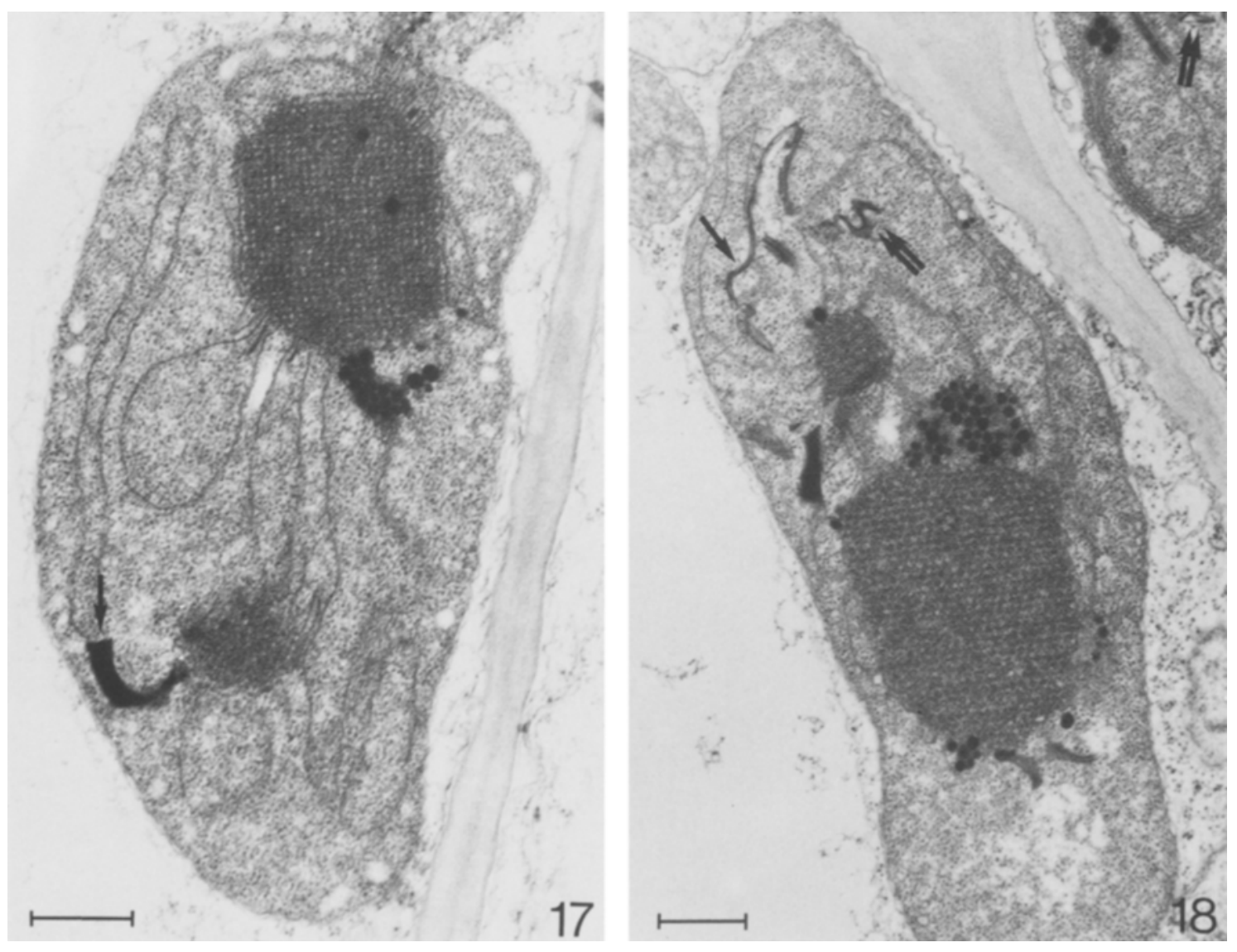

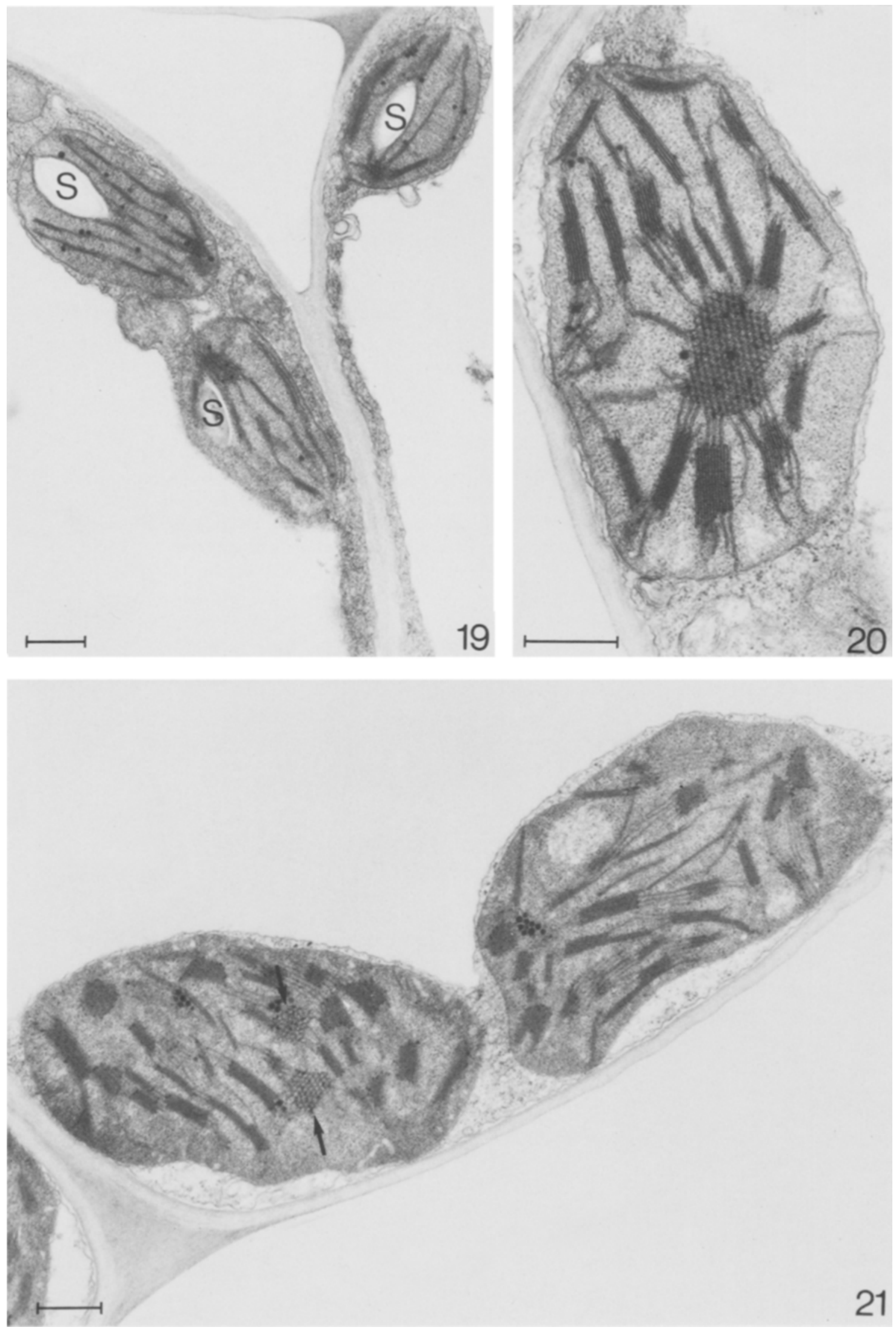
Figures 19 to 21 . Wild-type grown in $>650 \mathrm{~nm}$ red light.

A few membranes arranged into a thylakoid system with small prolamellar bodies are visible in the young plastids at level 1 (Figure 19). Starch granules (S) are also present in these plastids. An increase in the amount of membranes is found in plastids of level 2 (Figure 20), showing a simultaneous presence of prominent grana and paracrystalline prolamellar bodies. Prolamellar bodies are still found in some mature plastids at level 6 (Figure 21, arrows). (Bar $=0.5$ $\mu \mathrm{m})$.

in tigrina-o 34 grown under restrictive conditions is located in the electron-dense stacks. These abnormal grana may - as previously suggested (17) also be the site of the aberrant chlorophyll $a_{743}$ since only the top part of the mutant leaf contains chlorophyll $a_{743}$ and the electron dense stacks. As reported above (section 3.6) chlorophyll $a_{743}$ was found associated with lycopene and protein.

In wild-type leaves grown under $>600 \mathrm{~nm}$ red light, very young plastids at level 1 had both very small prolamellar bodies and grana (Figure 29). At level 2 the plastids thylakoid system appeared to be fairly well developed and arranged into grana and inter-grana lamellae (Figure 30). When present, prolamellar bodies were very small. Towards the leaf tip development of the thylakoid system proceeds and finally, at the leaf tip (level 6) mature chloroplasts with well-developed thylakoid systems were usually found (Figure 31).

In mutants grown under the $>600 \mathrm{~nm}$ red light aberrant structures were seen in plastids of all ages. At level 1 , close to the intercalary meristem, in the young plastids of the mutant leaf some undulating osmiophilic sheets were present (Figure 33). At level 2 most of the plastids were very aberrant with electron dense grana whereas some plastids contained exceptionally long grana (Figure 32). Ribosomes were still visible in the plastids of sections up to level 3. At this level plastids contained large undulating osmiophilic sheets as well as organised thylakoid membranes (Figure 34). The plastids at level 4 had an abnormal membrane structure with large electron-dense stacks and prolamellar bodies were frequent (Figure 35). As was the case in $>650 \mathrm{~nm}$ red light the large electron-dense stacks seen in Figure 35 must originate by self-condensation of the grana seen in Figure 34. Ribosomes were present in all plastids at this level, whereas at level 5 they were only present in some plastids (Figure 36). At this level vacuolation indicating plastid destruction was seen. Where the stroma appears disorganized ribosomes were no longer recognizable (Figures 37 and 38). In plastids at level 6 all membrane structures were abnormal and the stroma was completely disorganized. Thus, the decrease in the amount of $70 \mathrm{~S}$ ribosomes in the mutant grown in $>600 \mathrm{~nm}$ red light was confirmed by the electron microscopical results. Ribosome destruction occurred only in the higher intensity red light and was always preceeded by the appearance of aberrant membranes. When the ultrastructure of plastids in mutants grown under $>600 \mathrm{~nm}$ red light was compared with those grown under $>650 \mathrm{~nm}$ red light, plastid disorganisation and destruction was seen at earlier stages of plastid development (lower leaf levels). The greater stability of mutant plastids in the $>650 \mathrm{~nm}$ red light is correlated with the more balanced pigment content reported in section 3.3.

The study of the plastid ultrastucture revealed that plastid ribosomes were present in tigrina-o 34 grown in the dark at $23^{\circ} \mathrm{C}$ but were destroyed by $>600 \mathrm{~nm}$ red light. Abnormal membrane structures were formed by condensation of membranes of relatively normal appearance. In sections of light grown plants the amount of electron dense stacks was correlated with the content of chlorophyll $a_{743}$.

\subsection{The phenotype exhibited by tigrina and albozonata mutants under different growth conditions}

The sensitivity of the phenotype of tigrina-o 34 to temperature and light intensity suggested that it would be of interest to see if the phenotype of other tigrina mutants was also affected by these parameters.

In Figures $1 \mathrm{~A}$ and $1 \mathrm{~B}$ examples were shown of two tigrina mutants which illustrate the tigrina and zonata phenotypes. These phenotypes were only exhibited when tigrina and albozonata mutants were grown under alternating periods of light and dark (36) and in addition depended on the intensity and quality of the light and the temperature (Table V). 
For mutants grown at $23{ }^{\circ} \mathrm{C}$ using the higher intensity white light $\left(55 \mu \mathrm{E} \cdot \mathrm{m}^{-2} \cdot \mathrm{sec}^{-1}\right)$ in the light period a tigrina phenotype characterised all tigrina- $a$ and tigrina- $b$ mutants and tigrina- $d 12$, tigrina- $e^{21}$ and tigrina-o ${ }^{34}$, A zonata phenotype was shown by tigrina-n mutants whereas the mutant tigrina-fll showed a zonata phenotype with a tendency for necrosis. Alboviridis was the phenotype exhibited by tigrina-j28 and albozonata-l, while tigrina- $m^{31}$ was viridis and is known to develop a zonata phenotype under less favourable conditions (36).

When the white light intensity of the light period was decreased to $15 \mu \mathrm{E} \cdot \mathrm{m}^{-2} \cdot \mathrm{sec}^{-1}$ some mutants showed a less pronounced phenotype. In tigrina-d ${ }^{12}$, tigrina-e 21 , tigrina-f1l and tigrina$o^{34}$ the phenotype changes from tigrina to zonata; in tigrina- $n^{32}$ from zonata to viridis and tigrina- $n^{33}$ from zonata to viridoxantha. Therefore in these mutants, the higher light intensity resulted in a more severe phenotype attributed to photodestruction.
Figures 22 to 24 . The tigrina- $0^{34}$ mutant grown in $>650 \mathrm{~nm}$ red light.

Plastids of levels 1 (Figure 22), 2 (Figure 23) and 3 (Figure 24) are shown. As in the wild-type, in all these cases there is a simultaneous presence of prolamellar bodies and well developed grana. Plastid membranes have a normal appearance and ribosomes are visible in all the plastids. $(\mathrm{Bar}=0.5 \mu \mathrm{m})$.

When grown at $30^{\circ} \mathrm{C}$ compared to $23^{\circ} \mathrm{C}$ under light periods of identical intensity $\left(15 \mu \mathrm{E} \cdot \mathrm{m}^{-2} \cdot \mathrm{sec}^{-1}\right)$ some tigrina mutants were positively affected by the increase in temperature and became wild-type in appearance or tended to do so. These were tigrina-a $a^{3}$, and igrina-e 21 which were almost completely wild-type in appearance, tigrina-b24 where a wild-type phenotype with a suspicion of zonata was seen, while tigrina-j28 became viridis. The phenotype of tigrina $-o^{34}$ was viridis with faint banding.

The increase of temperature from $23{ }^{\circ} \mathrm{C}$ to $30{ }^{\circ} \mathrm{C}$ adversely affected the phenotype of four

Table V.

The effect of growth conditions on the expression of the tigrina and albozonata phenotypes. The phenotype was determined on the seventh day after sowing using photoperiods of 8 hours dark and 16 hours light. Light intensity is given as $\mu E \cdot m^{-2} \cdot \sec ^{-1}$. Mutants tig- $b^{24},-c^{20},-c^{25}$ and tig- - $28^{2}$ are homozygous viable. 1) With curled tips; $N D=$ not determined.

\begin{tabular}{|c|c|c|c|c|c|}
\hline & \multicolumn{3}{|c|}{ White light } & \multicolumn{2}{|c|}{ Red light } \\
\hline & & & & $>600 \mathrm{~nm}$ & $>650 \mathrm{~nm}$ \\
\hline & $23^{\circ} \mathrm{C}$ & $23^{\circ} \mathrm{C}$ & $30{ }^{\circ} \mathrm{C}$ & $23^{\circ} \mathrm{C}$ & $23^{\circ} \mathrm{C}$ \\
\hline & $55 \mu \mathrm{E}$ & $15 \mu \mathrm{E}$ & $15 \mu \mathrm{E}$ & $2.5 \mu \mathrm{E}$ & $1.4 \mu \mathrm{E}$ \\
\hline tig-al, $,-a^{6},-a^{13}$ & tigrina & tigrina & tigrina & tigrina & normal \\
\hline$-a^{17},-a^{18},-a^{22}$ & tigrina & ligrina & tigrina & tigrina & normal \\
\hline$t^{i g-a^{3}}$ & tigrina & tigrina & normail & tigrina & normal \\
\hline tig-b7 $,-b^{19},-b^{23}$ & tigrina & tigrina & tigrina & tigrina & normal \\
\hline$-b^{24}$ & tigrina & tigrina & zonata & normal & normal \\
\hline$t i g-c^{20},-c^{25}$ & normal & normal & normal & normal & normal \\
\hline$t i g-d 12$ & tigrina & zonata & tigrina & tigrina & normal \\
\hline$t i g-21$ & tigrina & zonata & normal "1) & pale & normal \\
\hline$\| i g-f 11$ & $\begin{array}{l}\text { tigrina/ } \\
\text { zonata }\end{array}$ & zonata & tigrina & tigrina & normal \\
\hline$i i g-j 28$ & alboviridis & zonata & viridis & viridis & vindis \\
\hline tig-m $m^{3 !}$ & viridis & viridis & xantha & viridis & vinidis \\
\hline tig-n $n^{32}$ & zonata & viridis & viridis & viridis & viridis \\
\hline tig-n33 & zonata & $\begin{array}{l}\text { virido/ } \\
\text { xantha }\end{array}$ & xantha & ND & viridis \\
\hline tig-o 34 & tigrina & zonata & $\begin{array}{l}\text { virido/ } \\
\text { zonata }\end{array}$ & tigrina & viridis \\
\hline albozonata-1 & alboviridis & viridis & albina & ND & viridis \\
\hline
\end{tabular}



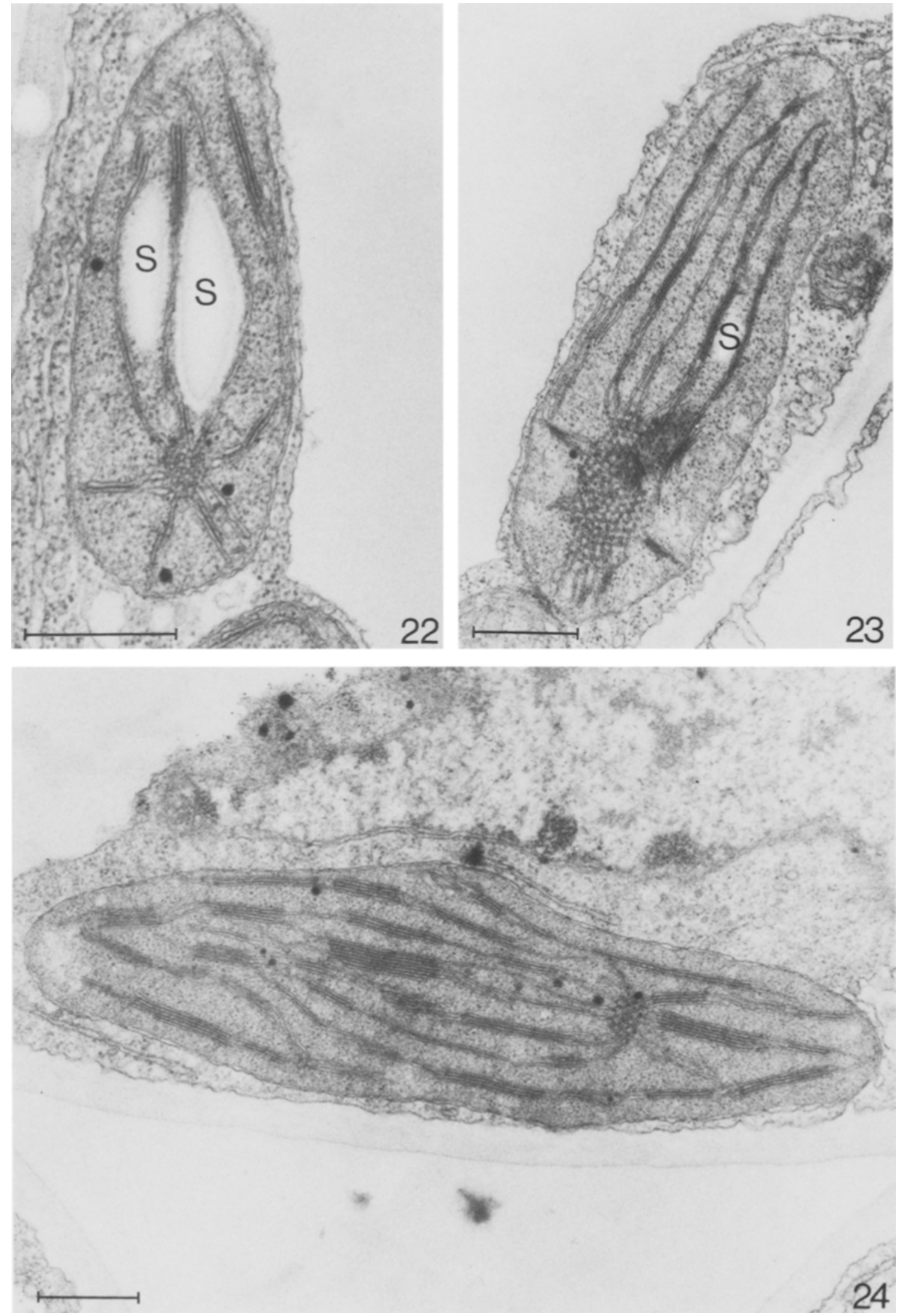

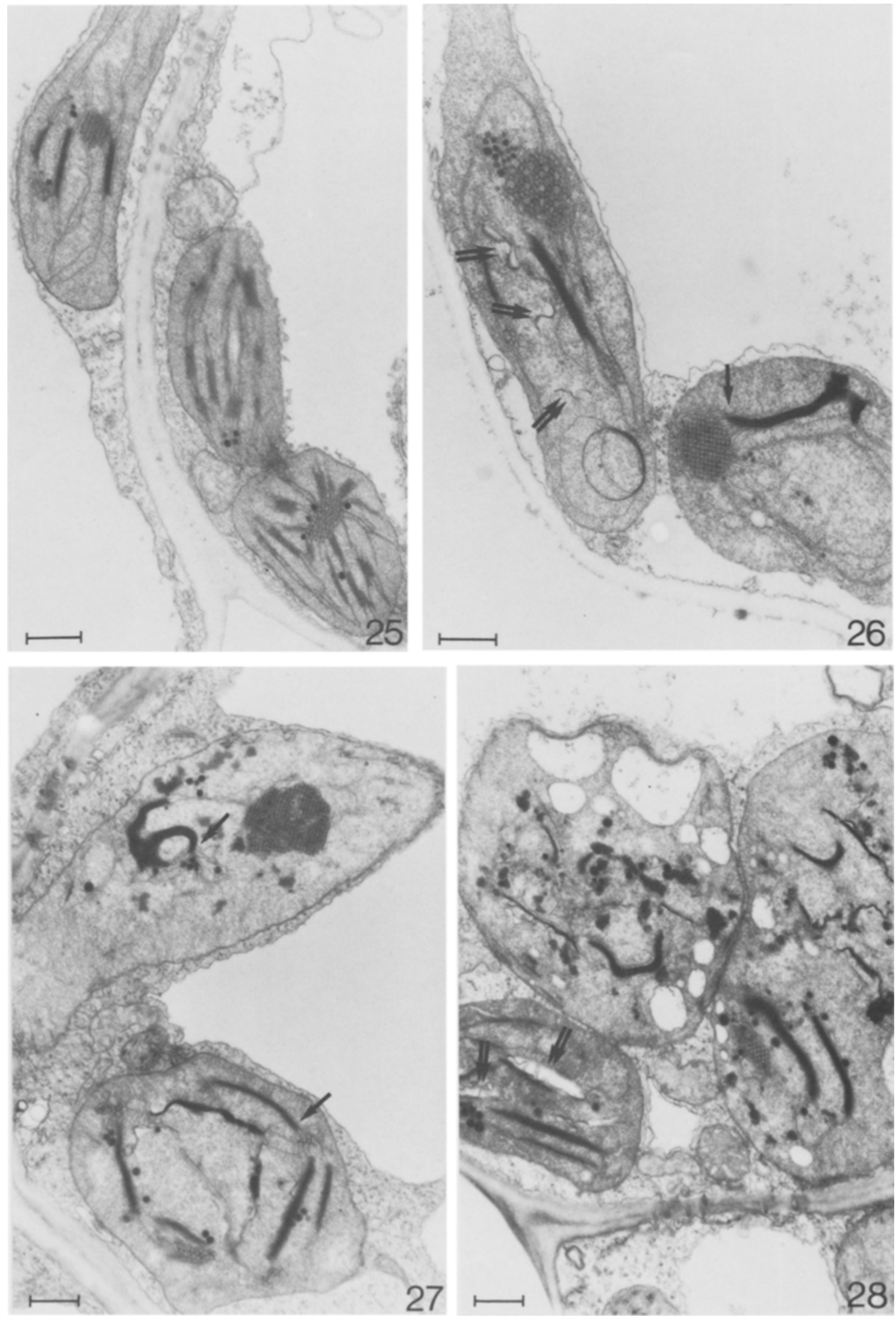
4 Figures 25 to 28 . The tigrina-o 34 mutant grown in $>650 \mathrm{~nm}$ red light.

At level 4 (Figures $25 \& 26$ ) both normal and abnormal plastids occur. Prolamellar bodies are present and in the abnormal plastids very electron-dense membrane stacks (Figure 26, arrow) as well as structures characteristic for lycopene accumulation (Figure 26, double arrow). Plastids typical of levels 5 and 6 are shown in Figures 27 and 28, respectively. All plastids are abnormal with electron-dense membrane stacks (arrow) and undulating osmiophilic sheets (double arrow). Plastid ribosomes are present in all of them. (Bar $=0.5 \mu \mathrm{m}$ ).

mutants. These were tigrina-d12 and tigrina- $f^{11}$ which developed a clear tigrina phenotype at the higher temperature. The mutants tigrina- $m^{31}$ and tigrina- $n^{33}$ developed xantha phenotypes and albozonata-1 showed an albina phenotype at $30{ }^{\circ} \mathrm{C}$. The mutants discussed in this paragraph and the one above are therefore either cold-sensitive or sensitive to higher temperatures.

In order to see if the phenotype of the mutants could be positively affected by a further decrease of the light intensity and/or by changing its quality plants were grown using red light periods at $23{ }^{\circ} \mathrm{C}$. Red lights used were of similar low intensity but different qualities: $>600 \mathrm{~nm}$ red light $\left(2.5 \mu \mathrm{E} \cdot \mathrm{m}^{-2} \cdot \mathrm{sec}^{-1}\right)$ and $>650 \mathrm{~nm}$ red light $\left(1.4 \mu \mathrm{E} \cdot \mathrm{m}^{-2} \cdot \mathrm{sec}^{-1}\right)$ light.

Under both low intensity lights protochlorophyllide photoconversion would limit chlorophyll synthesis (section 3.3) but any accumulation of photoinactive protochlorophyllide absorbing at $630 \mathrm{~nm}$ would not act as a photosensitiser in $>650 \mathrm{~nm}$ red light. Mutants which accumulate excess amounts of photoinactive protochlorophyllide in the dark period would not be photobleached when exposed to $>650 \mathrm{~nm}$ red light. The $>600 \mathrm{~nm}$ red light periods positively affected the phenotype of three tigrina mutants compared to the higher intensity $15 \mu \mathrm{E} \cdot \mathrm{m}^{-2} \cdot \mathrm{sec}^{-1}$ white light at $23^{\circ} \mathrm{C}$. Under $>600 \mathrm{~nm}$ red light tigrina- $b^{24}$ had a wild-type phenotype, tigrina- $e^{21}$ resembled the wild-type but had a paler green leaf base and tigrina-j 28 was viridis. The latter two mutants had also been noted to be sensitive to high intensity in the white light experiment.

Three mutants were adversely affected by growth under the $>600 \mathrm{~nm}$ red light compared to the white light of $15 \mu \mathrm{E} \cdot \mathrm{m}^{-2} \cdot \mathrm{sec}^{-1}$ at $23{ }^{\circ} \mathrm{C}$. These were: tigrina-d ${ }^{12}$, tigrina- $f^{11}$ and tigrina-o $o^{34}$ where the phenotype changed from zonata to tigrina. As these three mutants had previously been noted to be positively affected by a decrease in white light intensity they must be specifically sensitive to $>600 \mathrm{~nm}$ red light. This light is more intense in the $>600 \mathrm{~nm}$ region than the white light of $15 \mu \mathrm{E} \cdot \mathrm{m}^{-2} \cdot \mathrm{sec}^{-1}$.

The phenotype exhibited by some mutants clearly depended on the quality of the low intensity red light. When $>650 \mathrm{~nm}$ red light of approximately the same low intensity was used in the light periods instead of $>600 \mathrm{~nm}$ red light, many mutants changed phenotype from tigrina to wild-type. These were all tigrina- $a$ mutants, tigrina- $b^{7},-b^{19}$ and $-b^{23}$, tigrina-d ${ }^{12}$, and tigrina-f ${ }^{11}$; mutant tigrina-o ${ }^{34}$ changed from tigrina to viridis and tigrina-e 21 from wild-type with paler green leaf base to wild-type. These mutants are therefore specifically sensitive to $>600 \mathrm{~nm}$ red light.

It has been suggested that the bleached or necrotic bands observed in tigrina mutants are due to damage caused by a photosensitising pigment which accumulates in the dark but not in the light during extension growth (14). Nonphotoactive protochlorophyllide levels exceeding those of the wild-type are accumulated in tigrina-d ${ }^{12}$, the tigrina- $b$ mutants, tigrina-o ${ }^{34}$ and the tigrina-n mutants grown in complete darkness. This protochlorophyllide could account for their tigrina phenotype. The non-photoactive protochlorophyllide has an in vivo absorption maximum at $630 \mathrm{~nm}$. Accordingly, the above mentioned mutants should develop the tigrina phenotype when grown under light-dark cycles with $>600 \mathrm{~nm}$ and not with $>650 \mathrm{~nm}$ red light. The expected results were obtained with tigrina$d^{12}$, tigrina- $b^{7},-b^{19},-b^{23}$ and tigrina-o ${ }^{34}$. The mutants tigrina- $b^{24}$, tigrina- $n^{32}$ and $-n^{33}$ showed uniform leaf colour under both red lights. These three tigrina mutants are the ones which accumulates only twice as much or less protochlorophyllide in the dark (28) compared to the wild-type. The tigrina- $n$ mutants accumulate excess amounts of abnormal carotenes (29) and this could provide extra protection against a photosensitiser.

All tigrina- $a$ mutants and tigrina- $f^{11}$ behaved just as the majority of the protochlorophyllide 

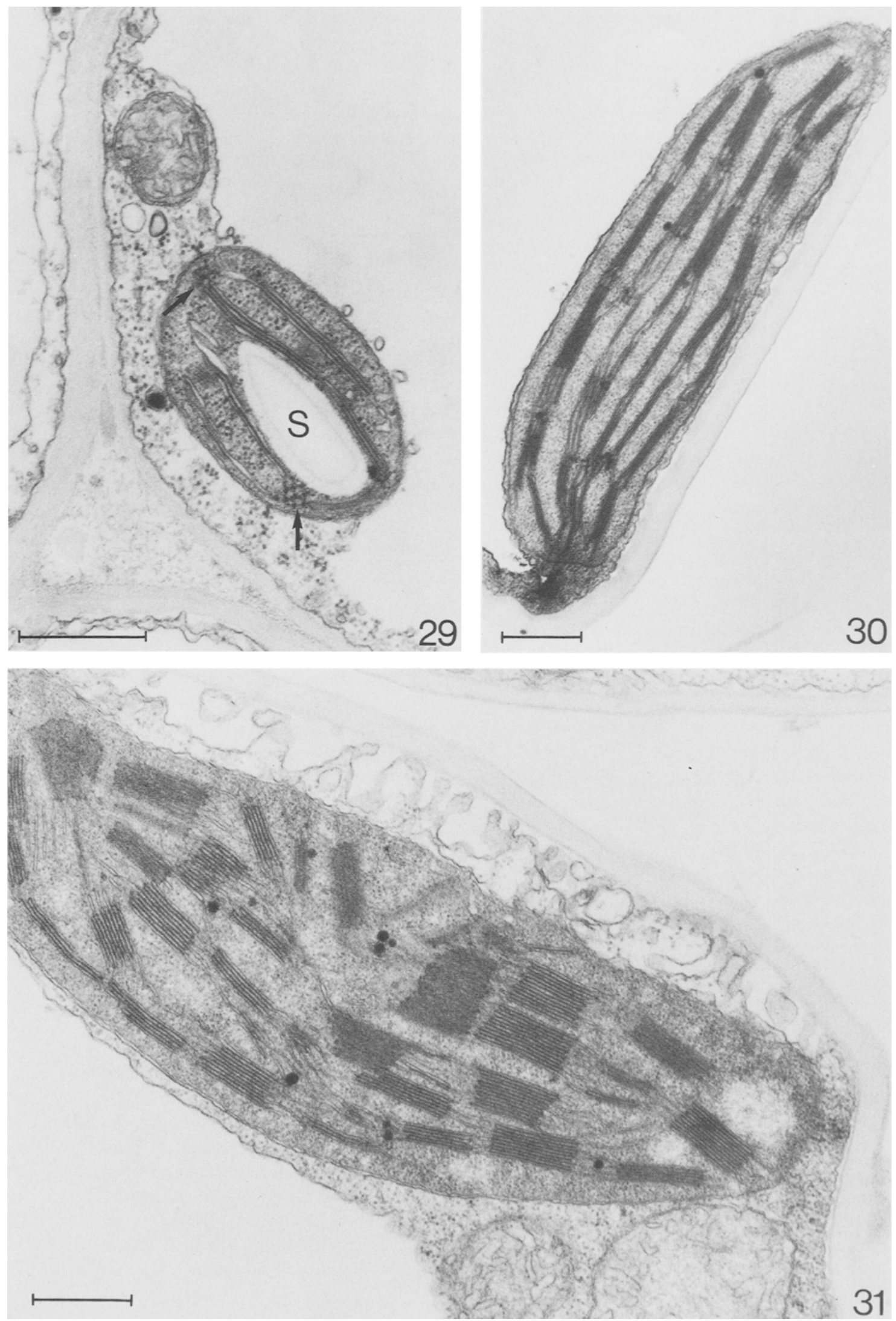
Figures 29 to 31 . Wild-type grown in $>600 \mathrm{~nm}$ red light.

At level 1 the young plastids contain prolamellar bodies (Figure 29, arrows) as well as grana and starch granules (S). The thylakoid system is more developed at level 2 (Figure 30). The internal membranes of the plastids are arranged into grana and inter-grana lamellae. Mature chloroplasts are found at level 6 (Figure 31). $(\mathrm{Bar}=0.5 \mu \mathrm{m})$.

accumulators and exhibited a tigrina phenotype under $>600 \mathrm{~nm}$ but not under $>650 \mathrm{~nm}$ red light-dark regime. These mutants do not accumulate protochlorophyllide when grown continuously in the dark (28). However, in tigrina-a, spectra of leaves indicate that protochlorophyllide accumulates in excess of wild-type only after it has been induced by light. The mutant tigrina-f 1 is carotenoid defective in the light. It may be predicted that this mutant will accumulate excess protochlorophyllide in the dark compared to the wild-type especially at higher temperatures since it showed a more severe phenotype at $30^{\circ} \mathrm{C}$.

The mutants tigrina- $j^{28}$ and tigrina- $n^{32}$, which are sensitive to light intensity and tigrina- $m^{31}$ which is temperature sensitive showed no differential response to the two red lights.

The tigrina- $c$ mutants showed a wild-type phenotype under all conditions tested and must require a lower temperature to exhibit a tigrina phenotype.

After seven days of growth under the $>650 \mathrm{~nm}$ red light/dark periods the plants were exposed to $55 \mu \mathrm{E} \cdot \mathrm{m}^{-2} \cdot \mathrm{sec}^{-1}$ white light for five minutes and returned to the previous growth conditions. Twenty-four hours later transverse bands which were paler green, yellowish or brownish-red compared to the rest of the leaf were seen in tigrina- $b^{7},-b^{19},-b^{23}$ and tigrina-o ${ }^{34}$. Thus in tigrina$b^{7}$ three yellow bands were seen corresponding to the three dark periods experienced by the leaf from its emergence on the fourth day until the seventh day. In tigrina-d ${ }^{12}$ a single band was seen. Photodestruction causing these bands must be due to the accumulation in the dark period of a photosensitising pigment, most probably protochlorophyllide. When grown in complete darkness at $23^{\circ} \mathrm{C}$ tigrina- $b^{7},-b^{19},-b^{23}$, tigrina- $d^{12}$ and tigrina-o 34 appear pale green due to ac- cumulation of excess protochlorophyllide (28). In tigrina-d 12 the accumulated pigment is dissipated with time. In the carotenoid deficient tigrina- $0^{34}$ and tigrina- $b$ mutants the appearance of chlorophyll deficient bands implies that the deficient regulation of the chlorophyll biosynthetic pathway in the dark has more severe effects than in the light. In continuous darkness or under continuous illumination all tigrina mutants exhibited a uniform leaf colour (28).

\section{DISCUSSION}

This discussion relates the defective carotenoid biosynthesis in tigrina-o $o^{34}$ and other tigrina mutants to: the regulation of chlorophyll biosynthesis, the formation of chlorophyll $a_{743}$ in the light, the formation of abnormal membranes and the defective synthesis in the plastid of membrane polypeptides.

It has been shown that both the regulation of $\delta$-aminolevulinate biosynthesis in the dark and the defective carotenoid biosynthesis in tigrina$o^{34}$ are cold-sensitive. Other tigrina mutants with defects in carotenoid biosynthesis which are associated with faulty regulation of $\delta$-aminolevulinate formation in the dark are tigrina- $b^{23}$ and mutants at the tigrina- $n$ locus where accumulation of excess protochlorophyllide indicates defective regulation of $\delta$-aminolevulinate formation $(28,29)$.

Therefore, the defective carotenoid biosynthesis and regulation of $\delta$-aminolevulinate formation may have a common cause. The $\delta$ aminolevulinate synthesising enzyme is strongly inhibited by heme $(14,15)$. Genetic evidence suggests that regulation of the $\delta$-aminolevulinate synthesising enzyme by heme in tigrin $a-b$ mutants and tigrina-o ${ }^{34}$ is defective $(14,21)$. Double mutants of these tigrinas with xantha-f10 accumulate the immediate heme precursor protoporphyrin, although xantha-f10 alone forms only minute amounts of protoporphyrin. Heme but not protoporphyrin inhibits the $\delta$ aminolevulinate synthesising enzyme of the wild-type and thus a defective regulation by heme in these two carotenoid deficient tigrina mutants is deduced. As heme containing enzymes are most probably required in the desaturation processes in carotenoid biosynthesis, a heme deficiency could explain the phenotypes 

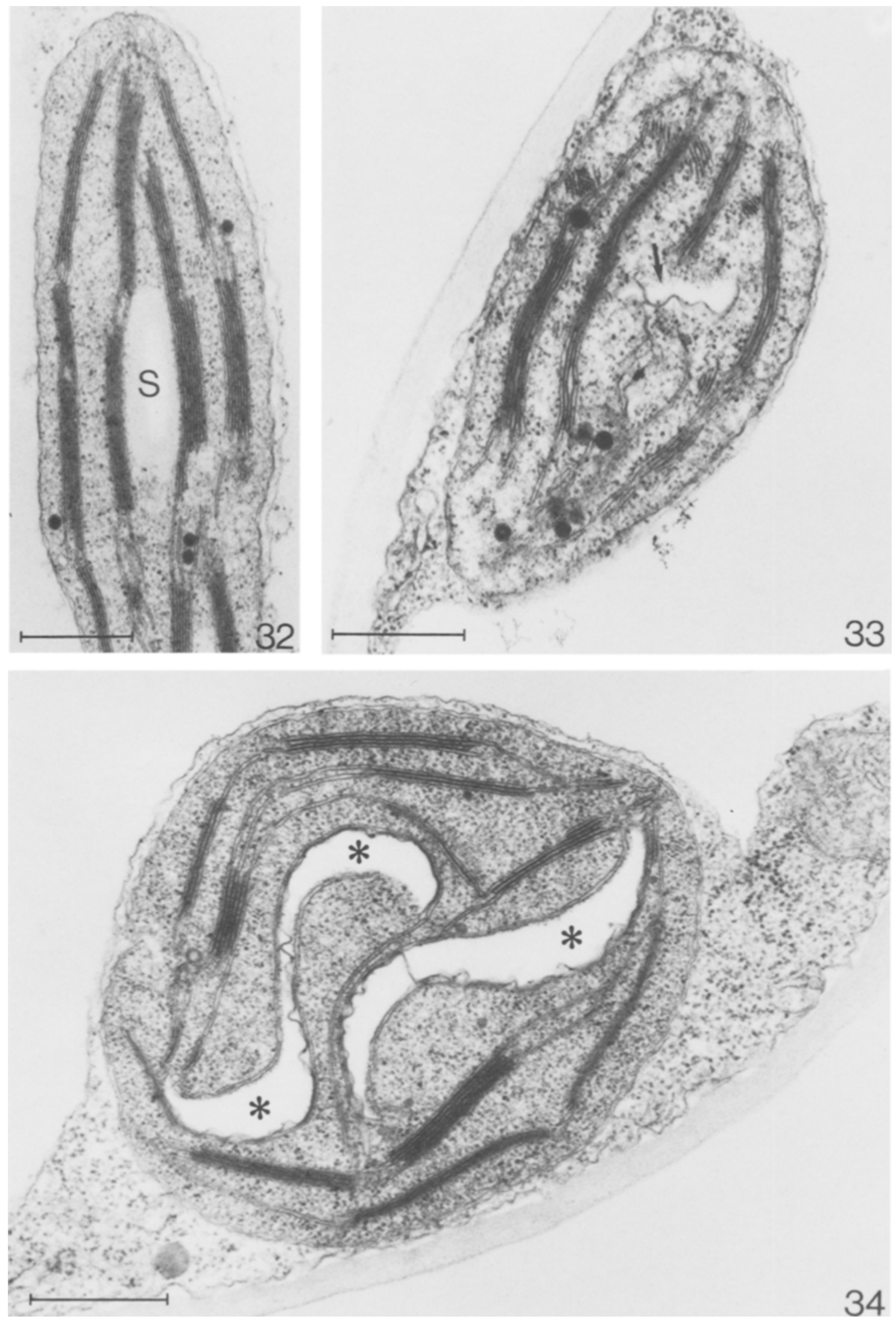
4 Figures 32 to 34 . The tigrina-o 34 mutant grown in $>600 \mathrm{~nm}$ red light.

Lycopene accumulations can already be seen in plastids at level 1 (Figure 33, arrow) but thylakoid membranes have a normal appearance. Normal plastids with starch granules (S) are found at level 2 (Figure 32). Large lycopene accumulations (Figure 34, asterisks) are present together with normal grana and inter-grana membranes. Plastid ribosomes are clearly visible in all these figures. (Bar $=0.5 \mu \mathrm{m}$ ).

of these carotenoid deficient tigrina mutants. When tigrina-o $0^{34}$ was grown at $30{ }^{\circ} \mathrm{C}$ under $>650 \mathrm{~nm}$ red light the chlorophyll and carotenoid content was indistinguishable from the wild-type.

The relationship of deficient carotenoid biosynthesis in tigrina mutants to the accumulation of chlorophyll $a_{743}$ has been investigated in this paper. The aberrant chlorophyll is also observed in tigrina- $b$ mutants, tigrina-f11, tigrina- $m^{31}$, tigrina- $n$ mutants and tigrina-o ${ }^{34}$ which are all now known to have partial blocks in carotene biosynthesis. No other tigrina mutants described have chlorophyll $a_{743}(28)$ or are known to have defects in carotenoid biosynthesis. The formation of chlorophyll $a_{743}$ has also been reported in wheat leaves treated with amitriole (20) which is an inhibitor of carotene biosynthesis (4). The observation that very little fluorescent emission attributable to chlorophyll $a_{743}$ could be observed in light grown tigrina-o ${ }^{34}$ leaves suggested that it is an aggregated form of chlorophyll. Dimers or aggregates of chlorophyll have been shown to exhibit a decreased fluorescence (30). It has been suggested that aggregated chlorophyll having an absorption at $740 \mathrm{~nm}$ is arranged as a stack of sheets of (-chlorophyll- $\mathrm{H}_{2} \mathrm{O}$-chlorophyll- $\left.\mathrm{H}_{2} \mathrm{O}\right)_{\mathrm{n}}$ (22). In tigrina-o $o^{34}$ chlorophyll $a_{743}$ is associated with lycopene and some unidentified protein. Aggregation of chlorophyll $a$ giving a form with an absorption maximum at $740 \mathrm{~nm}$ has been observed in non-polar solvents, is reversed by the xanthophyll, lutein, and by increases in temperature (2). This suggests that chlorophyll aggregation may also be caused by the lycopene accumulation (acting as a non-polar solvent) and lutein deficiency seen in light grown tigrina-o $0^{34}$ and most probably in the other tigrina mutants which have partial blocks in the carotenoid path- way prior to xanthophyll formation. In tigrina$o^{34}$ grown at $30^{\circ} \mathrm{C}$ in white light less chlorophyll $a_{743}$ was seen than at the lower growth temperatures. This decrease may be related to the increase in lutein and the increased content of the normal $\beta$-carotene relative to the abnormal lycopene. As shown in (2) increased temperature may also lead to deaggregation of the chlorophyll. If this is so, it is expected that carotenoid deficient tigrina mutants not affected by temperature such as tigrin $a-b^{7},-b^{19}$ and $-b^{23}$ should have less chlorophyll $a_{743}$ at $30^{\circ} \mathrm{C}$.

The photoinstability of pigments in tigrina-o 34 which can be attributed to the deficient carotenoid content leads to an instability of plastid ribosomes and plastid ultrastructure in general. In the light tigrina-o 34 is particularly deficient in $\beta$-carotene. In carotenoid deficient plants light absorbed by chlorophyll may result in the formation of singlet oxygen and cause photodamage $(1,9,23)$.

The defective $\beta$-carotene biosynthesis at the lower growth temperature resulted in photoinstability of tigrina-o ${ }^{34}$ plastids leading to destruction of plastid ribosomes. Previously it was shown that in white light at $30^{\circ} \mathrm{C}$ tigrina-o ${ }^{34}$ seedlings contained ribosomes in plastids throughout the entire leaf. However, in the light at $20^{\circ} \mathrm{C}$ chloroplast ribosomes were only seen in the very young plastids close to the intercalary meristem (17). Consequently in white light at $20^{\circ} \mathrm{C}$ chloroplast ribosomes are first formed and subsequently destroyed during plastid maturation due to carotenoid, primarily $\beta$-carotene, deficiency. At $30^{\circ} \mathrm{C}$ the increased level of $\beta$-carotene in the mutant protects $70 \mathrm{~S}$ ribosomes from photodamage. The photodestruction of plastid ribosomes has previously been demonstrated in $\beta$-carotene deficient mutants of sunflower (35) as well as in wheat and rye where carotenoid deficiency has been induced by herbicides $(3,8)$.

In tigrina-o 034 the destruction of chloroplast ribosomes is a light mediated process. The red light experiments showed that the intensity and the wave-length of light also influenced the stability of the ribosomes in plants grown at $23^{\circ} \mathrm{C}$. The $>600 \mathrm{~nm}$ red light was more damaging to tigrina-o $o^{34}$ than the $>650 \mathrm{~nm}$ red light. The more severe damage to pigments, ribosomes and generally to plastid ultrastructure seen under the 

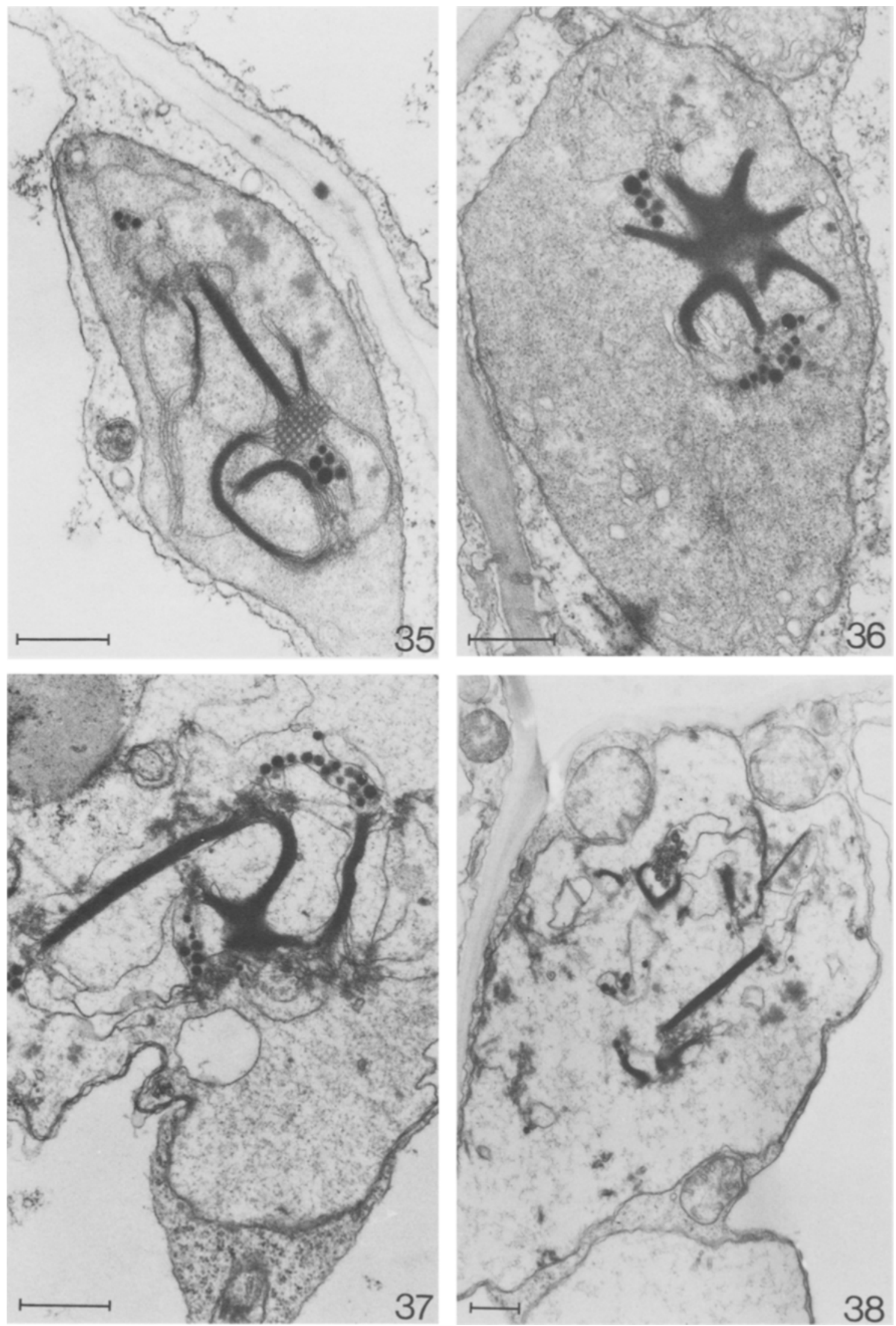
4 Figures 35 to 38 . The tigrina-o $0^{34}$ mutant grown in $>600$ nm red light.

All plastids are aberrant at level 4 with very electron-dense large stacks formed by membranes radiating from a prolamellar body (Figure 35 ). Plastids with normal stroma and ribosomes (Figure 36) are present together with plastids containing disorganised stroma and no clearly recognizable ribosomes (Figure 37) at level 5. At level 6 no ribosomes can be seen and the stroma is completely disorganised (Figure 38$)$. (Bar = $0.5 \mu \mathrm{m})$.

$>600 \mathrm{~nm}$ red light than under the $>650 \mathrm{~nm}$ light can be attributed to the greater light intensity which results in an increased action of both chlorophyll $a$ and $b$ as photosensitisers. Successive increase in chlorophyll concentration during plastid maturation leads to the increase in photodamage seen from the bottom to the tip of the leaf.

The aberrant membrane structures seen in some of the tigrina mutants can be related to disturbances in carotenoid biosynthesis.

The accumulation of lycopene and/or other more saturated carotenes is always associated with the occurrence of crystalloids, osmiophilic granules, and undulating osmiophilic sheets (28). Investigations on the ultrastucture and pigment composition of mutant plastids from plants grown in the dark or under low intensity $>650 \mathrm{~nm}$ red light compared to the higher intensity $600 \mathrm{~nm}$ red light confirmed that abnormal membrane structures were not due to photodestruction but to the defective carotenoid biosynthesis.

The undulating membranes seen in tigrina-o ${ }^{34}$ plastids may be explained by the lycopene accumulation. Lycopene is believed to form crystalloids in the plastids and when these crystalloids dissolve during dehydration with ethanol after fixation the surrounding membranes are left behind as the undulating osmiophilic membranes (33). The electron dense stacks seen in tigrina-o $0^{34}$ are interpreted in the present paper as result of condensation of membranes due to the presence of lycopene and deficiency of $\beta$-carotene and xanthophylls.

The presence of membrane polypeptides known to be synthesised on chloroplast ribosomes in plastid membranes from tigrina- $o^{34}$ was dependent only on the growth temperature and not on the presence of chloroplast ribosomes in the plastids. Although these ribosomes were present in mutants grown in the dark or under $>650 \mathrm{~nm}$ red light they apparently functioned more effectively at $30^{\circ} \mathrm{C}$ than at $23^{\circ} \mathrm{C}$. Evidence suggested that the protein composition of $70 \mathrm{~S}$ ribosomes was normal at both temperatures. Deficiency of these membrane polypeptides must be related to the carotenoid deficiency in tigrina$o^{34}$ which has been shown to lead to abnormal membranes in the plastid. It has been shown that polysomes are bound to chloroplast membranes, and such membrane bound polysomes have been found to be active in protein synthesis in vitro, when supplemented with soluble cofactors $(5,11,26)$. In Chlamydomonas unfinished products of such protein synthesis have been shown to be bound to the thylakoid membranes $(11,26$, 27). The abnormal membranes could hinder insertion of membrane polypeptides either by inhibiting their synthesis or by by preventing attachment of plastid ribosomes. It will therefore be of interest to see if the missing membrane polypeptides accumulate in the plastid stroma.

\section{ACKNOWLEDGEMENTS}

We wish to thank Professor DITER vON WeTtstein, Professor Andy Wang and Dr. Albert KAHN for stimulating discussions and Dr. BIRGER Lindberg Mølter for making the low temperature fluorescence spectra. Bibi STAMPE ANDERSEN, Hanne Them Nielsen, Nina Rasmussen, Jean SAGE and ANN-Sofi Steinholtz are thanked for skilful technical assistance. Financial support was provided by the Commission of European Communities, contract No. ESD-013-DK(G) of the Solar Energy Programme to Professor Diter VON WetTSTEIN.

\section{REFERENCES}

1. Anderson, S.M. \& N.I. Krinsky: Protective action of carotenoid pigments against photodynamic damage to liposomes. Photochem. Photobiol. 18, 403-408 (1973)

2. ARONOFF, S.: The interaction of chlorophyll dimers with lutein. Ann. N.Y.Acad.Sci.244,320326 ( 1975)

3. Bartels, P.G., K. Matsuda, A. Siegel \& T.E. WEIER: Chloroplastic ribosome formation: Inhibition by 3-amino-1,2,4 triazole. Plant Physiol. $42,736-741$ (1967) 
4. Burns, E.A., G.A. Buchanan \& M.C. Carter: Inhibition of carotenoid synthesis as a mechanism of action of amitriole, dichloromate and pyrichlor. Plant. Physiol. 47, 144-148 (1971)

5. Chua, N.-H., G. Blobel, P. Siekevitz \& G.E. PALADE: Periodic variations in the ratio of free to thylakoid-bound chloroplast ribosomes during the cell cycle of Chlamydomonas reinhardii. J. Cell. Biol. 71, 497-514 (1976)

6. Davis, B.H.: Carotenoids. In: Chemistry and biochemistry of plant pigments. Vol. 2, T.W. Goodwin ed., Academic Press, New York, pp. 38-165 (1976)

7. Eskins, K. \& H.J. DutTon: Sample preparation for high performance liquid chromatography of higher plant pigments. Anal. Chem. 51, 1885-1886 (1979)

8. Feierabend, J., U. Schulz, P. Kemmerich \& T. Lowirz: On the action of chlorosis-inducing herbicides in leaves. Z. Naturforsch. 34c, 10361039 (1979)

9. FoOte, C.S., R.W. DenNy, L. Weaver, Y. Chang \& J. Peters: Quenching of singlet oxygen. In: Ann. N.Y. Acad. Sci. 171, pp. 139-148 (1970)

10. Foster, R.J., G.C. Gibbons, S. Gough, K.W. Henningsen, A. Kahn, O.F. Nielsen \& D. von WetTSTEIN: Protochlorophyllide holochrome. In: Proceedings of the first European Biophysics Congress. E. Broda et al. eds., Viennese Academy of Medicine, Vienna, vol. 4, pp. 134-149 (1971)

11. Gillham, N.W.: Organelle Heredity. Raven Press, New York, pp. 104-109 (1978)

12. Girnth, C., S.P. Gough \& C.G. Kannangara: $\Delta$-aminolevulinate synthesis in greening barley. 3. Characterisation of regulatory mutants. In: Proc. Sth Int. Congr. Photosyn. 1980. G. Akoyunoglou ed. Balaban Int. Sci. Serv, Philadelphia, pp. 129-136 (1981)

13. Gough, S.: Defective synthesis of porphyrins in barley plastids caused by mutation in nuclear genes. Biochim. Biophys. Acta 286, 36-54 (1972)

14. Gough, S.P. \& C.G. Kannangara: Biosynthesis of $\delta$-aminolevulinate in tigrina mutants of barley. Carlsberg Res. Commun. 44, 403416 (1979)

15. Gough, S.P., C. Girnth \& C.G. Kannangara: $\Delta$-aminolevulinate synthesis in greening barley. 1. Regulation. In: Proc. 5th Int. Congr. Photosyn. 1980. G. Akoyunoglou ed. Balaban Int. Sci. Serv., Philadelphia, pp. 107-116 (1981)

16. Henningsen, K.W. \& J.E. Boynton: Mac- romolecular physiology of plastids VII. Pigment and membrane formation in plastids of barley greening under low light intensity. J. Cell. Biol. 44, 290-304 (1970)

17. Høyer-HaNSEN, G. \& G. CASADORO: Unstable chloroplast ribosomes in the cold-sensitive barley mutant tigrina-o34. Carlsberg Res. Commun. 47, 103-118 (1982)

18. Høyer-HANSEN, G. \& D.J. Simpson: Changes in the polypeptide composition of internal membranes of barley plastids during greening. Carlsberg Res. Commun. 42, 379-389 (1977)

19. Ikan, R.: Natural Products. Academic Press, New York, pp. 96-99 (1969)

20. Inoue, Y., T. Ogawa \& K. Shibata: A far red absorbing form of chlorophyll formed by the action of aminotriazole. Plant \& Cell Physiol. $13,385-389$ (1972)

21. KAHN, A.N. Avivi-Bleiser \& D. voN WetTSTEIN: Genetic regulation of chlorophyll biosynthesis analysed with double mutants in barley. In: Genetics and biogenesis of Chloroplasts and Mitochondria. Th.Bücher et al. eds., Elsevier/North Holland, Amsterdam, pp. 119131 (1976)

22. KaTZ, J.J.: The state of chlorophyll in photosystem I, photosystem II and the light harvesting unit. In: Chlorophyll Organisation and Energy Transfer in Photosynthesis. Excerpta Medica, Amsterdam, pp. 344-348 (1979)

23. KRINSKY, N.I.: The protective function of carotenoid pigments. In: Photophysiology Current Topics, A.C. Giese ed., Vol III. Academic Press, New York, pp. 123-195 (1968)

24. LiCHTENTHALER, H.K.: Light stimulated synthesis of plastid quinones and pigments in etiolated barley seedlings. Biochim. Biophys. Acta 184, 164-172 (1969)

25. MCKInNeY, G.: Absorption of light by chlorophyll solutions. J. Biol. Chem. 140, 315-322 (1941)

26. Margulies, M.M. \& A. Michaels: Free and membrane bound chloroplast polyribosomes in Chlamydomonas reinhardii. Biochim. Biophys. Acta 402,297- 308 (1975)

27. Margulies, M.M., H.L. Tiffany \& A. MiCHAELS: Vectorial discharge of nascent polypeptides attached to chloroplast thylakoid membranes. Biochem. Biophys. Res. Commun. 64, 735 (1975)

28. NiELSEN, O.F.: Macromolecular physiology of plastids XII. Tigrina mutants in barley. Genetic, spectroscopic and structural characterisation. Hereditas 76, 269-304 (1974) 
29. NielseN, O.F. \& S.P. Gough: Macromolecular physiology of plastids XI. Carotenes in etiolated tigrina and xantha mutants of barley. Physiol. Plant. 30, 246-254 (1974)

30. SAUER, K.: Primary events and the trapping of energy. In: Bioenergetics of Photosynthesis. Govindjee, ed., Academic Press, New York p. $136(1975)$

31. Simpson, D.J.: Freeze-fracture studies on barley plastid membranes. III. Location of the light-harvesting chlorophyll-protein. Carlsberg Res. Commun. 44, 305-336 (1979)

32. Simpson, D.J. \& D. voN WetTSTEIN: Macromolecular physiology of plastids. XIV. Viridis mutants in barley: Genetic, fluoroscopic and ultrastructural characterization. Carlsberg Res. Commun. 45, 283-314 (1980)

33. Simpson, D.J., C.O. Chichester \& T.H. LeE: Chemical regulation of plastid development I. Inhibition of chlorophyll biosynthesis in detached pumpkin cotyledons by CPTA. A pig- ment and ultrastructural study. Aust. J. Pl. Physiol. 1, 119-133 (1974)

34. Simpson, D.J., G. Høyer-Hansen, N.-H. Chua \& D. VON WETTSTEIN: The use of gene mutants in barley to correlate thylakoid polypeptide composition with the structure of the photosynthetic membrane, Proc. 4th Int. Photosyn. Cong., Reading pp. 537-548 (1977)

35. WALLES, B.: An electron microscope study on photodestruction of plastid ribosomes in $\beta$-carotene-deficient mutants of Helianthus annus $\mathbf{L}$. Protoplasma 75, 215-227 (1972)

36. Wettstein, D. von \& K. Kristiansen: Stock list of nuclear gene mutants affecting the chloroplast. Barley Genet. Newslett. 3, 113-117 (1973)

37. Wettstein, D. von, A. KaHN, O.F. NIELSEN \& S. GovGH: Genetic regulation of chlorophyll synthesis analysed with mutants of barley. Science $184,800-802$ (1974) 